San Jose State University

SJSU ScholarWorks

Master's Theses

Master's Theses and Graduate Research

Spring 2015

\title{
The Development of a Small Scale Wind Tunnel Simulating the Atmospheric Boundary Layer
}

Maximillian Hobson-Dupont

San Jose State University

Follow this and additional works at: https://scholarworks.sjsu.edu/etd_theses

\section{Recommended Citation}

Hobson-Dupont, Maximillian, "The Development of a Small Scale Wind Tunnel Simulating the Atmospheric Boundary Layer" (2015). Master's Theses. 4543.

DOI: https://doi.org/10.31979/etd.ugb8-8ujc

https://scholarworks.sjsu.edu/etd_theses/4543

This Thesis is brought to you for free and open access by the Master's Theses and Graduate Research at SJSU ScholarWorks. It has been accepted for inclusion in Master's Theses by an authorized administrator of SJSU ScholarWorks. For more information, please contact scholarworks@sjsu.edu. 
THE DEVELOPMENT OF A SMALL SCALE WIND TUNNEL SIMULATING THE ATMOSPHERIC BOUNDARY LAYER IN SUPPORT OF A STOCHASTIC WIND MODEL

\author{
A Thesis \\ Presented to \\ The Faculty of the Department of Mechanical Engineering \\ San José State University \\ In Partial Fulfillment \\ of the Requirements for the Degree \\ Master of Science \\ in \\ Mechanical Engineering
}

by

Maximillian Hobson-Dupont

May 2015 
(C) 2015

Maximillian Hobson-Dupont

ALL RIGHTS RESERVED 
San José State University

The Undersigned Committee Approves the Thesis Titled

THE DEVELOPMENT AND CHARACTERIZATION OF A SMALL SCALE WIND TUNNEL SIMULATING THE ATMOSPHERIC BOUNDARY LAYER

by

Maximillian Hobson-Dupont

APPROVED FOR THE DEPARTMENT OF MECHANICAL ENGINEERING SAN JOSÉ STATE UNIVERSITY

May 2015

Dr. Jinny Rhee

Department of Mechanical Engineering

Dr. Kamran Turkoglu

Department of Aerospace Engineering

Dr. Eduardo Chan

Department of Mechanical Engineering 


\begin{abstract}
THE DEVELOPMENT OF A SMALL SCALE WIND TUNNEL SIMULATING THE ATMOSPHERIC BOUNDARY LAYER
\end{abstract}

By Maximillian Hobson-Dupont

There has been much success in atmospheric boundary layer simulation with medium sized closed-circuit wind tunnels with test section dimensions of approximately $1 \mathrm{x}$ $1 \mathrm{~m}$. However, smaller, blower-type wind tunnels are more common in university laboratories due to the lower cost and smaller space requirements. A small size, open flow wind tunnel with a $1 \times 1$ foot test section was modified to simulate the atmospheric boundary layer with a combination of upstream spires and cubic roughness elements. The primitive spire geometry detailed in the literature was found to yield poor agreement with the power law velocity profile of interest, and a novel iterative algorithm was developed to produce nonlinear spire geometry. The geometry generated by the algorithm was tested in the wind tunnel and found to simulate the desired velocity profile based on a Hellman exponent of 0.20 with a high degree of agreement, having a maximum velocity error of $4 \%$. This confirmed the suitability of small-sized wind tunnels for simulating the atmospheric boundary layer. 


\section{ACKNOWLEDGEMENTS}

I would like to thank Dr. Jinny Rhee for being a first rate mentor and committee chair. Dr. Rhee's words of encouragement and direction helped keep the project on track through numerous setbacks and difficulties. I would like to thank Dr. Eduardo Chan for serving on my thesis committee and for helping me realize how much I enjoy numerical simulations. I would also like to thank Dr. Kamran Turkoglu for agreeing to be on my committee.

Roger Jue has been of tremendous assistance in keeping the lab running and procuring any equipment needed. He is a great resource to the Mechanical Engineering Department. Lastly, I would like to thank Dr. Valery Martynov, for all of the "soviet" given over the past several years. 


\section{TABLE OF CONTENTS}

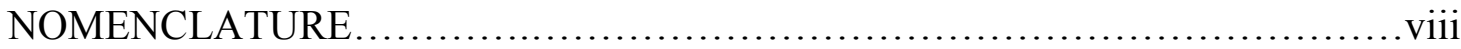

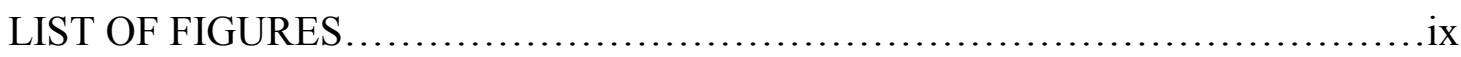

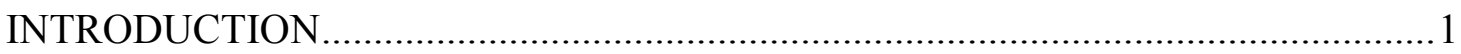

Microlayer..................................................................................... 2

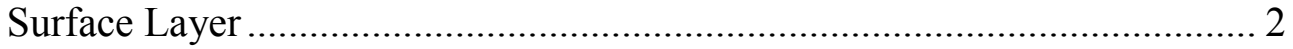

Convective Mixed Layer.................................................................... 2

Literature Review ............................................................................ 4

Fluid dynamics in the ABL..................................................... 4

Velocity Profile in the ABL............................................................... 5

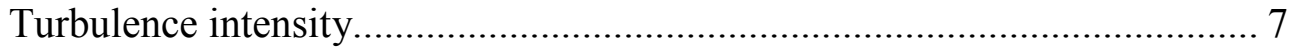

Turbulence power spectrum.......................................................... 7

Use of wind tunnels to simulate the ABL......................................... 8

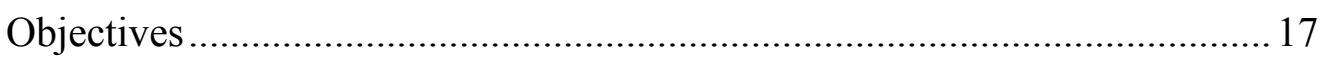

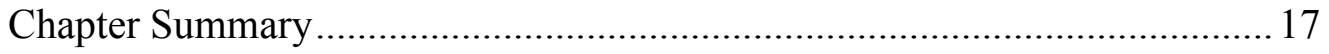

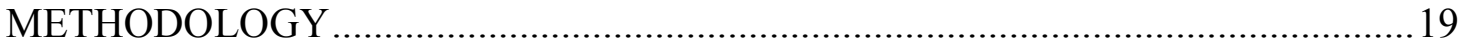

Wind Tunnel Velocity Measurements....................................................... 19

Velocity measurement calculations. ................................................. 19

Pitot-static system validation. ................................................... 20

Tunnel Flow Simulations .............................................................. 21

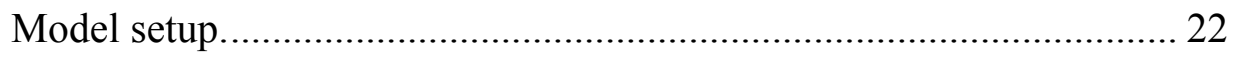

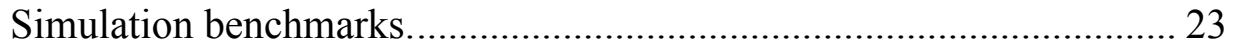

ATMOSPHERIC BOUNDARY LAYER WIND TUNNEL DEVELOPMENT .........27

Modified Wind Tunnel Aerodynamics and Small Wind Tunnel Validation .. 27

Roughness fetch development. ................................................... 33 
Generation of Spire Geometry .......................................................... 36

Characteristics of the simulated boundary layer................................ 36

First spire design: based on literature …......................................... 36

Geometry Adaption Algorithm ............................................................... 40

Spire Designs Two and Three .............................................................. 43

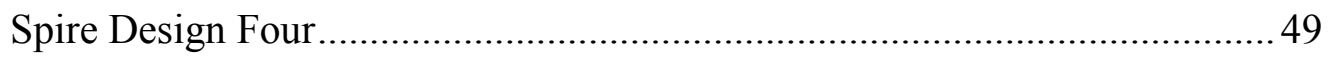

Characteristics of the Simulated Wind Tunnel..............................................5 54

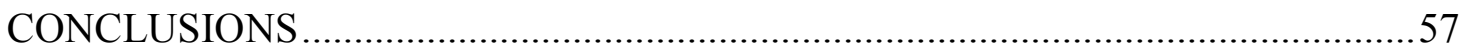

References........................................................... 58

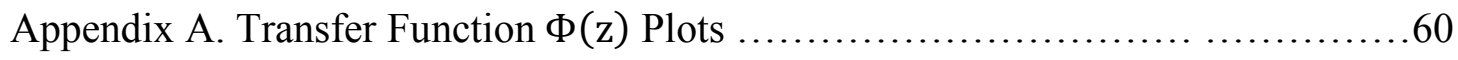

Appendix B. 1:2 Scale Drawings of Spire Profiles.............................61 
NOMENCLATURE

$\begin{array}{cl}\text { Symbols } & \text { Meaning } \\ z & \text { Height, altitude } \\ z_{0} & \text { Aerodynamic roughness } \\ m_{,} \alpha & \text { Power law exponent } \\ \bar{e} & \text { Turbulent kinetic energy (TKE) } \\ \rho & \text { Density } \\ \sigma_{A} & \text { Standard deviation } \\ h & \text { Height } \\ \lambda & \text { Eddy diameter } \\ P, \mathrm{p} & \text { Pressure } \\ g & \text { Acceleration due to gravity } \\ \bar{U}_{x} & \text { Mean wind velocity in x direction } \\ U_{x} & \text { Wind velocity in x direction } \\ u_{x} & \text { Turbulent component of velocity in } \mathrm{x} \text { direction } \\ \mu & \text { Viscosity } \\ \dot{m} & \text { Mass flow rate } \\ \mathrm{n}, \mathrm{f} & \text { Frequency (Hz) } \\ \delta & \text { Boundary layer height } \\ \chi & \text { Spire sizing parameter 1 } \\ \beta & \text { Spire sizing parameter } 2 \\ b & \text { Spire base dimension } \\ h & \text { Spire height dimension } \\ H & \text { Wind tunnel test section height } \\ C_{f} & \text { Skin friction coefficient } \\ k & \text { Cubic roughness element height } \\ \mathrm{I} & \text { Turbulence intensity } \\ S_{u} & \text { Autospectral density function for turbulence } \\ L_{1 u} & \text { Von Karman spectrum length scale } \\ L_{2 u} & \text { Kaimal spectrum length scale } \\ R e & \text { Reynolds number } \\ D & \text { Diameter } \\ \Psi & \text { Spire geometry parameter } \\ \Phi & \text { Velocity profile transfer function } \\ \mathrm{S} & \text { Spire contribution function } \\ \mathrm{C} & \text { Roughness fetch contribution function } \\ \mathrm{E} & \text { Power law velocity profile error function } \\ & \end{array}$

Subscripts

r Reference

D Diametrical 


\section{LIST OF FIGURES}

Figure 1. Open channel turbulent fluid flow

Figure 2. Multi-jet grid used by Teunissen (1975). Grid shown removed from wind

tunnel. Taken from published article with permission from publisher...

Figure 3. Triangular and elliptic vortex generators investigated by Counihan (1969).

Taken from published article with permission from publisher.

Figure 4. Counihan's (1969) ABL wind tunnel. Elliptical vortex generators are seen upstream of the test section. Tunnel dimensions: 5 feet $\mathrm{x} 2$ feet $\mathrm{x} 7.3$ inches. Taken from published article with permission from publisher.

Figure 5. Irwin's (1980) ABL simulating geometry for wind tunnels. Taken from published article with permission from publisher.

Figure 6. ABL wind tunnel from Lopes et al. (2009). Taken from published article with permission from publisher. 16

Figure 7. Apparatus for validating pitot-static tube. A calibrated jet was blown onto the pitot-static tube 20

Figure 8. Pitot-static tube validation results. 21

Figure 9. ABL wind tunnel simulation configuration. The computational domain (gray) shows significant problem size reduction using symmetry.

Figure 10. Benchmark analysis computational domain. Numerical reproduction of experiment conducted by Lopes et al. (2008). 24 
Figure 11. Benchmark analysis mesh details. Close up of spire mesh (left) and roughness fetch mesh (right). Tetrahedral elements were used for the spire and hexahedral for the fetch.

Figure 12. CFD benchmark analysis results comparison. 25

Figure 13. Turbulence intensity profile for CFD simulation and experiment. 26

Figure 14. Modified SJSU ME Department wind tunnel. Test section extended 3 feet to yield a 5:1 aspect ratio.

Figure 15. Boundary layer thickness growth. Growth along wind tunnel walls for a freestream velocity of $41 \mathrm{~m} / \mathrm{s}$. Assumes applicability of flat plate solution. 29 Figure 16. Corner-effect quantification simulation computational domain. Two symmetry planes were implemented to reduce the computational domain to a $45^{\circ}$ wedge. 30

Figure 17. Comparison with flat plate theory. Excellent agreement found between theory, experiment, and numerical simulation. 31 Figure 18. CFD velocity results. Boundary layer growth on vertical wall (top); Test section outlet freestream velocity percentage (lower left). Red contour indicates 99\%

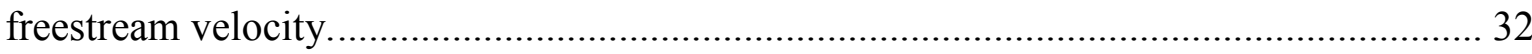

Figure 19. Expected usable test section. Truncated portion hashed.............................. 33

Figure 20. Roughness fetch installed in wind tunnel...................................................... 34

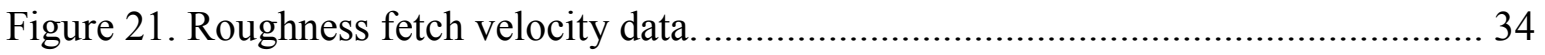

Figure 22. Velocity Profile for Roughness Fetch. A power law with $\alpha=0.28$ is simulated with reasonable agreement. 35 
Figure 23. First iteration of ABL simulation geometry. Parameters calculated from Irwin's (1981) guidelines. Dimensions in inches.

Figure 24. 3D printed spire construction. Initial difficulties (left). Final product (center). ABS FDM process used (right). 38

Figure 25. Measured velocity data for first iteration of geometry. 38

Figure 26. Measured velocity profile for first iteration of geometry. Poor agreement with the desired power law profile ( $\alpha=0.20$, in yellow). Thicker boundary layer $(\alpha=0.34)$ plotted in green for reference.

Figure 27. Geometric parameters of spire array. Algorithm solves for $\Psi_{z}$.

Figure 28. Calculated transfer function for first iteration of geometry. Points with a value of less than 0.6 were excluded from shape function calculation. 44 Figure 29. V2 spire geometry. Based on experimental testing of V1 geometry and algorithm output. 45

Figure 30. V2 geometry CFD results. Maximum power law error reduced by $12 \%$ from previous iteration. 46

Figure 31 . V3 spire geometry. Geometry optimized based on CFD simulation of V2 geometry

Figure 32. V3 geometry simulation results. Maximum error further reduced $6 \%$ from previous iteration. 48

Figure 33. V4 spire geometry. A conservative shape update relaxation factor was chosen.

Figure 34. CAD model of V4 geometry. Notch introduced into tail to increase dynamic structural response to flow. 50 
Figure 35. Final iteration of spire geometry. Spires were $3 \mathrm{~d}$ printed in two halves and joined together with acetone.

Figure 36. Experimentally measured velocity profile for final geometry iteration.

Shape produced by update algorithm yielded excellent agreement with power law

Figure 37. Velocity Plot for Final Geometry Iteration.

Figure 38. CFD computed turbulence intensity profile. Results are from the test section mid-plane. 55 


\section{INTRODUCTION}

Over the past several centuries, fossil fuel power generation has dominated energy production worldwide. This has had deleterious effects, both environmentally and economically. While fossil fuels are expected to remain the most prevalent energy source

for the foreseeable future, their overall share of net global energy production is expected to shrink while renewable energy sources are projected to grow. Renewable energy use is already growing by $2.5 \%$ annually (International Energy Outlook, 2013).

The source of the vast majority of alternative energy is the sun, either directly or indirectly. Photovoltaic cells use solar radiation to induce a current in semiconductors. This current is either stored for later use or directly used to perform useful work. Solar heating uses the sun's electromagnetic radiation, converting it to thermal energy. This thermal energy is used directly for heating or converted to useful work using one of the thermodynamic cycles. Alternatively, wind energy generation systems typically use large turbines to extract kinetic energy from wind currents. The majority of this kinetic energy comes from pressure gradients due to differential solar heating of the Earth's surface.

The nature of both solar and wind energy sources necessitates that power generation systems be exposed to the elements and that their constituent mechanisms, sub-systems, and structures are able to withstand the stresses induced by the environment. Frequently, the most severe structural and thermal loading is due to the wind flowing over the surface of the earth. This is known as the atmospheric boundary layer (ABL). 
The ABL exists as the boundary of air between the Earth's surface and its freeatmosphere. It is characterized by being responsive to surface forcings with a time period of $1 \mathrm{~h}$ or less (Stull, 1988), and its properties can vary remarkably with the time of day. The ABL consists of several layers, each exhibiting different characteristics. The formation of these layers is a function of both altitude and surface forcings and, consequently, of time.

\section{Microlayer}

The microlayer exists from the surface to the first several centimeters of altitude and remains for all times of day. It is characterized by a lack of turbulence, with molecular transport being the primary flux mechanism.

\section{Surface layer}

The surface layer consists of the atmosphere from the top of the microlayer to approximately $100 \mathrm{~m}$ of altitude, and it is characterized as having turbulence as the primary flux mechanism. It exhibits minimal variation (less than $10 \%$ ) in turbulent fluxes with respect to altitude (Stull, 1988). The surface layer also exists at all times of the day.

\section{Convective mixed layer}

The convective mixed layer occurs from above the surface layer to approximately $1200 \mathrm{~m}$ of altitude, start of the free atmosphere. Turbulence is by far the most dominating flux-generating mechanism, and as its name suggests, convection is the primary source of turbulence. Radiative solar heating of the ground produces convective heating from the earth's surface to the atmosphere, producing eddies. Additionally, radiative cooling of 
clouds at the top of the convective mixed layer results in convective cooling of the atmosphere, also producing eddies. The convective mixed layer exists during daytime hours.

An important parameter of the convective mixed layer is its stability, which varies with time. As air currents advect across the surface of the ground, they also translate upwards and downwards, increasing and decreasing their altitude, respectively. This behavior depends on the state-variable quantities of the air, such as temperature and humiditiy, as well as external forcings. The layer's stability is dependent on how these altitude perturbations change the turbulent kinetic energy (TKE) of the fluid. If an altitude perturbation increases the quantity of TKE, the layer is unstable. If an altitude perturbation decreases the amount of TKE, the layer is stable. If there is little to no TKE change due to an altitude perturbation, the layer has neutral stability. A detailed theoretical treatment of convective mixed layer stability is out of the scope of this work; however, the stability is due to the sign and quantity of the buoyancy generation term in the TKE budget equation.

Around sunset, turbulence decays resulting in the nocturnal boundary layer near the surface layer (approximately 100 to $400 \mathrm{~m}$ ), and the residual layer for the remainder of the ABL (approximately 500 to $1400 \mathrm{~m}$ ). The nocturnal boundary layer typically contains much less energy than the convective layer, with the residual layer containing even less. Additionally, the majority of the alternative energy power generation systems of interest reside in the surface layer. These last two layers are mentioned only for completeness and are ignored for the remainder of this work. 


\section{Literature Review}

The enormous importance of the ABL has resulted in a large amount of research in the field. Work relating to the characterization and study of the ABL fluid dynamics is presented in this chapter. Wind tunnels that simulate the ABL share the same components with conventional wind tunnels but with several significant design differences. Conventional aerodynamic wind tunnels are designed to effect a uniform flow field through their test section, whereas ABL-simulating wind tunnels use various methods to modify the flow, inducing a specific velocity gradient and quantity of turbulence in the test section. Efforts of researchers to induce these conditions are also presented in this chapter.

\section{Fluid dynamics in the ABL.}

Outside of the microlayer, fluid flow in the ABL always has some degree of turbulence. The mathematical description of turbulent flows is a complex one, and the nature of atmospheric fluid flows results in large problem domains and nonlinear boundary conditions. As such, no general case analytic solutions exist, and the physical description of ABL fluid flow is mostly based on fitting empirical data to simplified expressions for flow variables.

A common simplification to make is decomposing velocity into its mean and turbulent components (Stull, 1988):

$$
U=\bar{U}_{x}+\bar{U}_{y}+\bar{U}_{z}+u_{x}+u_{y}+u_{z}
$$

with $\bar{U}$ being the average velocity and $u$ being the turbulent component defined in Equation

2. 


$$
u=U-\bar{U}
$$

\section{Velocity Profile in the $A B L$.}

ABL flow can be likened to turbulent boundary layer flow in an open channel:

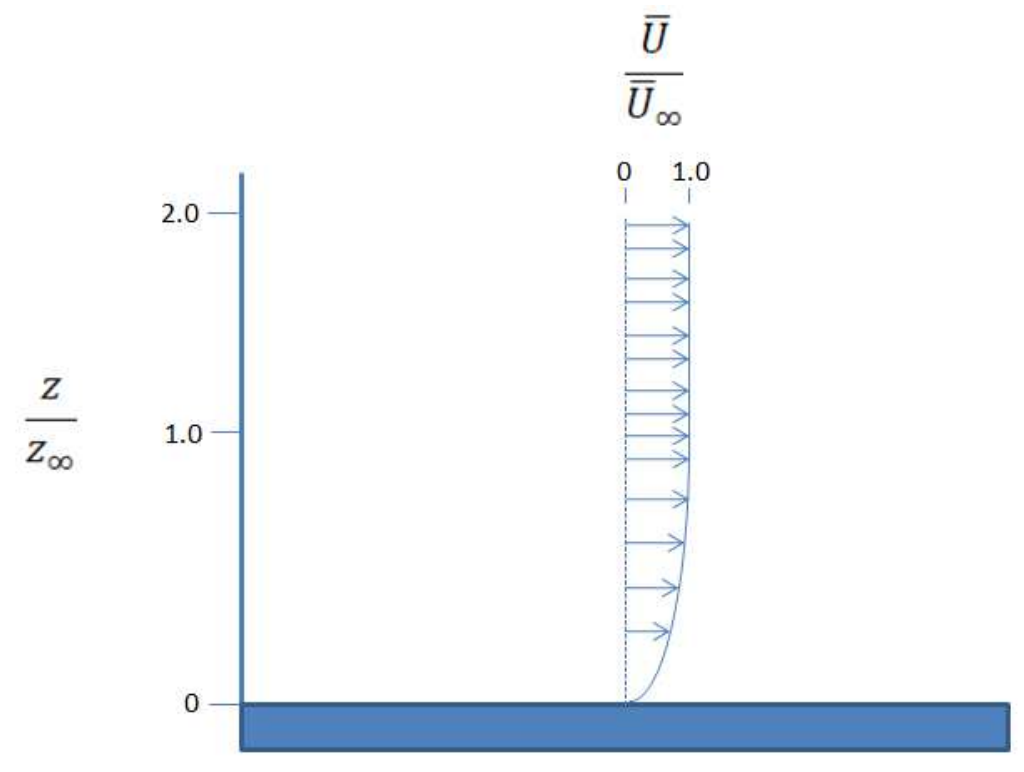

Figure 1. Open channel turbulent fluid flow.

Classical boundary layer theory yields the following expression for approximating the velocity profile:

$$
\frac{\bar{U}}{\bar{U}_{\infty}}=\left(\frac{Z}{z_{\infty}}\right)^{m}
$$

with $\bar{U}$ being the average velocity and $z$ being the height above the plate, and subscript $\infty$ meaning at the boundary layer. The exponent $m$ depends on the roughness of the plate surface. Prandtl found a value of one-seventh for smooth plates (Eckert, 2006). 
For use in describing the ABL velocity profile, Equation 2 is modified slightly, with the following form, first proposed by Hellman (1916):

$$
\frac{\bar{U}}{\bar{U}_{r}}=\left(\frac{z}{z_{r}}\right)^{m}
$$

where $r$ indicates a reference altitude, usually taken to be $10 \mathrm{~m}$ (Arya, 1988). Values for $m$ typically encountered in modeling ABL flows range from values of less than 0.1 for extreme wind conditions (Burton, et al, 2011), to values approaching 1 for exceptionally stable conditions (Arya, 1988), and depend largely on the characteristics of the surface and the stability of the convective layer. A number of characteristic values can be seen in Table 1.

Table 1

Hellman Exponent Values

\begin{tabular}{|l|l|l|r|}
\hline \multicolumn{1}{|c|}{ Terrain } & \multicolumn{1}{c|}{$\mathbf{z 0}(\mathbf{m})$} & \multicolumn{1}{c|}{ Stability } & \multicolumn{1}{c|}{$\mathbf{~}$} \\
\hline Open Water & $0.0001-0.0006$ & Unstable & $\mathbf{0 . 0 6}$ \\
\hline Rural & 0.024 & Unstable & $\mathbf{0 . 0 8}$ \\
\hline Rural & 0.024 & Unstable & $\mathbf{0 . 0 9}$ \\
\hline Open Water & $0.0001-0.0006$ & Neutral & $\mathbf{0 . 1}$ \\
\hline Flat Coastal & $0.0005-0.0015$ & Unstable & $\mathbf{0 . 1 1}$ \\
\hline Rural/Suburban & 0.07 & Neutral & $\mathbf{0 . 2}$ \\
\hline Rural/Suburban & 0.07 & Stable & $\mathbf{0 . 2 6}$ \\
\hline Flat Coastal & $0.0005-0.0015$ & Stable & $\mathbf{0 . 2 7}$ \\
\hline Urban & $2-3$ & Unstable & $\mathbf{0 . 2 7}$ \\
\hline Urban & $2-3$ & Neutral & $\mathbf{0 . 3 4}$ \\
\hline Flat Coastal & $0.0005-0.0015$ & Stable & $\mathbf{0 . 4}$ \\
\hline Suburban & 0.3 & Very Stable & $\mathbf{0 . 5 4}$ \\
\hline Urban & $2-3$ & Stable & $\mathbf{0 . 6}$ \\
\hline
\end{tabular}

Note. Data taken from Izumi, Caughey (1976) and Kaltschmitt, Wolfgang, Streicher, Wiese (2007). 


\section{Turbulence intensity.}

The turbulent component of velocity is constantly fluctuating. One method for quantifying the fluctuations is a statistical tool known as variance, defined by

$$
\sigma_{A}^{2}=\frac{1}{N} \sum_{i=0}^{N-1} u_{i}^{2}
$$

where $u_{i}$ is the $i$ th measurement in a series of $N$ measurements. The standard deviation of turbulent velocity, $\sigma_{A}^{2}$, is solved by taking the square root of the variance. The square root of variance is used to compute the turbulence intensity

$$
I=\sigma_{a} / \bar{U}
$$

Turbulence intensity in the surface layer typically varies by less than $10 \%$ (Stull, 1988 ) and has values of $10-20 \%$ for a neutrally stable convective layer and above $20 \%$ for an unstable convective layer (Arya, 1988).

\section{Turbulence power spectrum.}

The von Karman expression is the most commonly used method (Burton, et al., 2011) for generating turbulence spectra for a given environment (Equation 7).

$$
n \frac{S_{u}(n)}{\sigma_{u}^{2}}=\frac{4 n \frac{L_{1 u}}{\bar{U}}}{\left(1+70.8\left(n \frac{L_{1 u}}{\bar{U}}\right)^{2}\right)^{\frac{5}{6}}}
$$

with $L_{1 u}$ being a length scale. The International Electrotechnical Committee (1999) specifies an expression of $2.45^{*} \mathrm{z}$ for altitudes less than $30 \mathrm{~m}$. 
It has been suggested by Petersen et al. (1998) that the Kaimal spectrum function (Equation 7) yields a more accurate turbulence spectrum for the atmospheric boundary layer.

$$
n \frac{S_{u}(n)}{\sigma_{u}^{2}}=\frac{4 n \frac{L_{2 u}}{\bar{U}}}{\left(1+6 n \frac{L_{2 u}}{\bar{U}}\right)^{\frac{5}{3}}}
$$

with $L_{2 u}$ being a different length scale. Burton et al. (2011) references a length scale of $L_{2 u}=5 z$ for $z<30 \mathrm{~m}$.

\section{Use of wind tunnels to simulate the ABL.}

The first method developed for simulating ABL flows in wind tunnels was the use of an arrangement of roughness elements, which mimic the characteristics of the Earth's surface. These roughness elements are typically a simple geometric shape, such as a cube or a cylinder, although some researchers such as Counihan (1973) and Benson (2005) have used Lego ${ }^{\mathrm{TM}}$ building blocks with success.

It is generally agreed among researchers in the field that using roughness elements yields the best adherence of wind tunnel velocity gradients and the power and logarithmic velocity laws (Bortoli et al., 2002). As air flows over the roughness elements, turbulent eddies are formed, analogous to wind flowing over surface structures such as vegetation, dunes, and waves. This induces both a velocity gradient and turbulence into the flow. There is abundant literature relating the desired velocity gradient and turbulence intensity to test hardware parameters, such as roughness element geometry, size, spacing, and overall length of the roughness element section (fetch length).

Peterson et al. (1978) suggested an approximate fetch length of 100 times the roughness element height, finding it to be valid for roughness elements around $0.1 \mathrm{~m}$ in 
height. Wieringa (1993) reviewed the experimental results from over 50 peer-reviewed works on roughness element ABL simulation. He suggested the following expression for the required minimum fetch length:

$$
F \approx 2 z_{0}\left(\frac{10 z}{z_{0}}\left[\ln \frac{10 z}{z_{0}}-1\right]+1\right)
$$

with $z$ being the height of interest. He found that this relation yields acceptable agreement with the experimental results from a number of different roughness element length scales.

There exists a region of airflow just above the roughness cubes that exhibits high spatial variance of velocity in all three directions (not just with respect to height, as is desired for ABL simulation) and is called the roughness sublayer. Benson (2005) cites an approximate roughness sublayer height of 3 - 5 times the roughness element height. Cheng and Castro (2002) were among the first researchers to specifically investigate the roughness sublayer height. They measured the roughness sublayer characteristics for a variety of roughness element geometries and configurations. Laser Doppler Anemometry was used to validate results from a hot wire anemometer. The researchers found the ratio of roughness sublayer height to geometric height to range from $1.8-2.5$.

Choosing a roughness element height of 0.5 inches results in a maximum roughness sublayer height of 1.25 inches. Given that the wind tunnel being used has a $12 \times 12$ inch cross section, a reasonable value for z (Equation 9) might be 8 inches. Plugging these values into Wiering's relation results in a required fetch length of 653.0 inches, or 54.4 feet. This is clearly too long given that the aim of the project is to simulate ABL flows in a small scale wind tunnel. 
Teunissen (1975) investigated using a grid of jets to simulate ABL flow. A total of 64 nozzles, 0.245 inches in diameter, was used in an 8 by 8 grid. Each jet was electronically controlled to modulate fluid output. A trial-and-error approach was used to induce desired velocity profiles.

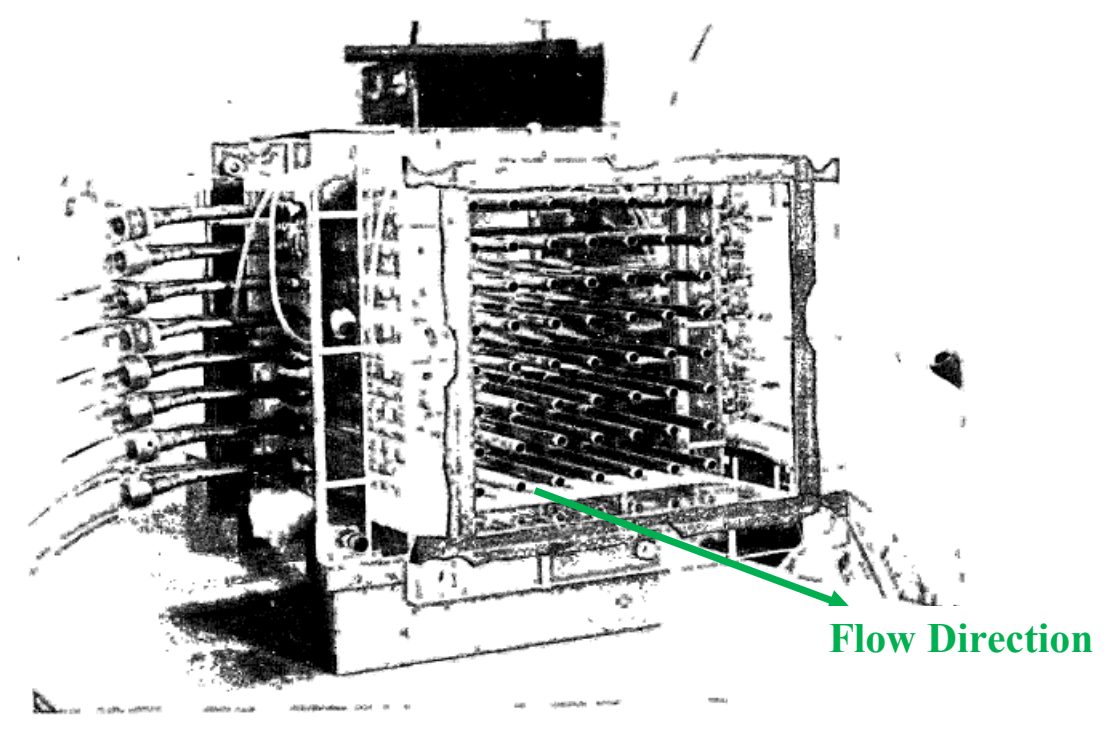

Figure 2. Multi-jet grid used by Teunissen (1975). Grid shown removed from wind tunnel. Taken from published article with permission from publisher.

It was found that the system worked remarkably well for simulating ABL velocity profiles, and could be configured to precisely match a wide range of Hellman exponent values. This velocity profile was found to be stable from a length of 2.5 times the test section height. The performance of the system fell short in inducing turbulence into the flow. A number of methods were evaluated. The flowrates of the columns of jets were modulated, with columns alternating from $10 \%$ above nominal output to $10 \%$ below nominal. This was found to increase turbulence near the jet exit plane, but this turbulence quickly decayed to experimentally insignificant values. The use of roughness elements was tried, but the problem of insufficient roughness fetch length resulted in acceptable turbulence intensity values too close to the boundary to be of any experimental use. Finally 
a 1-inch aluminum plate was installed along the lower wall at a length of 2 times the test section height. This was found to induce sufficient turbulence at a length of 6.75 times the height. It was also found that a 1.5 inch barrier made velocity profile control impossible. A multiple jet grid wind tunnel has a number of advantages, namely the ability to accurately induce practically any velocity profile into the tunnel flow. However, it requires a complex control system and a significant investment in required test equipment. Smallscale wind tunnels are advantageous because of their efficiency and low cost. It is likely that an institution performing research with a small-scale wind tunnel would look to use experimental apparatuses that are low in both complexity and price of implementation. Counihan (1969) attempted to circumvent the extensive roughness fetch length requirements of roughness element $\mathrm{ABL}$ simulation by investigating the usage of elliptic and triangular vortex generators (Figure 3) to "thicken" the boundary layer. 


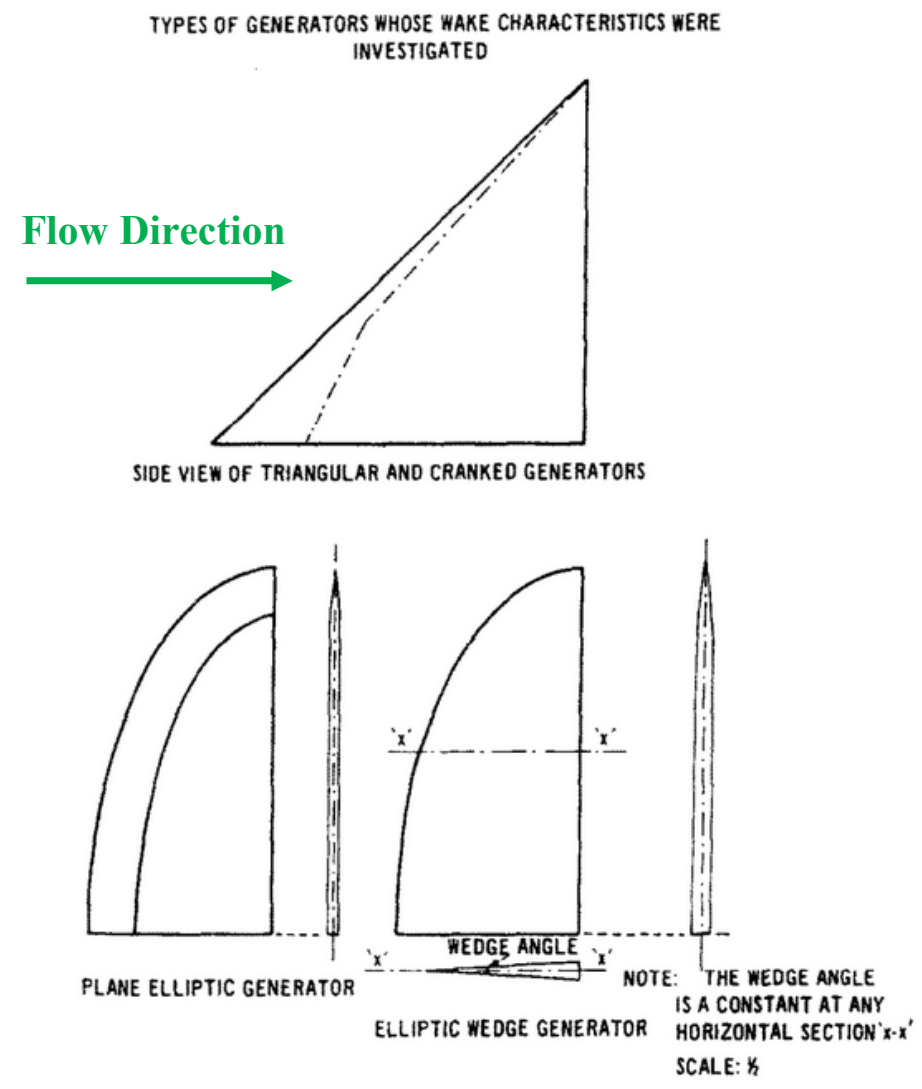

Figure 3. Triangular and elliptic vortex generators investigated by Counihan (1969). Taken from published article with permission from publisher.

The specific geometry was taken from earlier work performed by the author, with

minor modifications made. Experiments were carried out in a wind tunnel with a test section 5 feet long, 2 feet wide and 7.3 inches high. Counihan (1969) initially tested the geometries without any other geometric features or roughness elements. Starting with the triangular geometry, he measured the turbulence intensity directly downstream of the vortex generators. He found that the gradient of turbulence was unacceptably high, which was suspected to be due to excessive momentum loss around the middle of the generator and insufficient momentum loss at the top and bottom. An elliptic shape was then tried, as it was suspected that this would smooth the turbulence gradient. This indeed was the case 
and the author proceeded to exclusively test elliptic geometries, in conjunction with Lego $^{\mathrm{TM}}$ roughness elements and a 0.75 inch high barrier.

It was found that this combination of geometries was capable of inducing a velocity profile with acceptable agreement with the power law having a Hellman exponent value of $1 / 7$, equivalent to a smooth plate or a rural environment boundary layer with neutral convection stability.

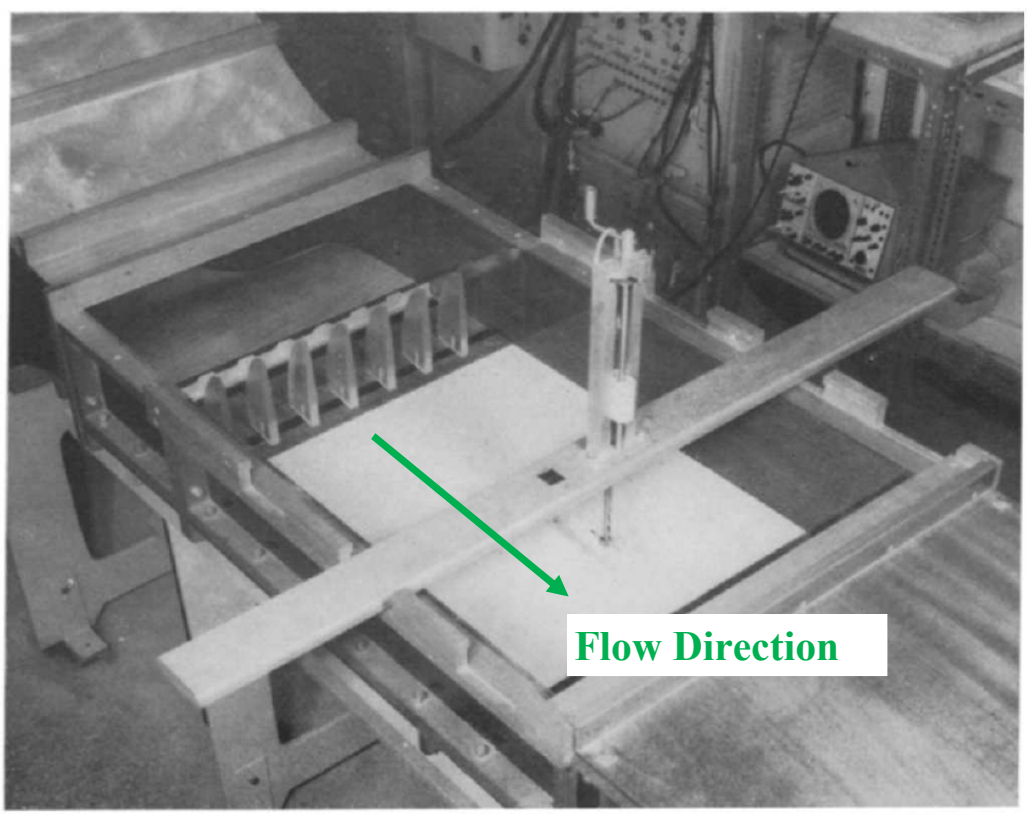

Figure 4. Counihan's (1969) ABL wind tunnel. Elliptical vortex generators are seen upstream of the test section. Tunnel dimensions: 5 feet $\mathrm{x} 2$ feet $\times 7.3$ inches. Taken from published article with permission from publisher.

I believe that Counihan rejected the usage of triangular vortex generators prematurely. While describing the geometry of a simple ellipse is easy enough (minor and major radii), accurately fabricating them is tricky. Producing a triangle shape is less difficult, and allows for more rapid experimentation with how the geometric parameters affect flow characteristics. 
Counihan's concern over excessive turbulence gradients may be unfounded. Those measurements were taken with a smooth lower wall, when in actual ABL simulation usage, roughness elements and barrier walls were used. Turbulent flow is highly nonlinear, and there is no such thing as "eddy superposition." It is suspected that the eddies from the three sources will interact, and in doing so diffuse TKE throughout the produced boundary layer, reducing the turbulence intensity gradient. This is also evident by the success that other researchers have had with triangular elements, in both $\mathrm{ABL}$ velocity and turbulence profile simulation.

In his paper, Irwin (1980) speaks to his years of experience in developing spire geometry for ABL wind tunnel simulation. He identifies a number of equations and a method for producing triangular spire and roughness element geometry based on a desired Hellman exponent and boundary layer height.

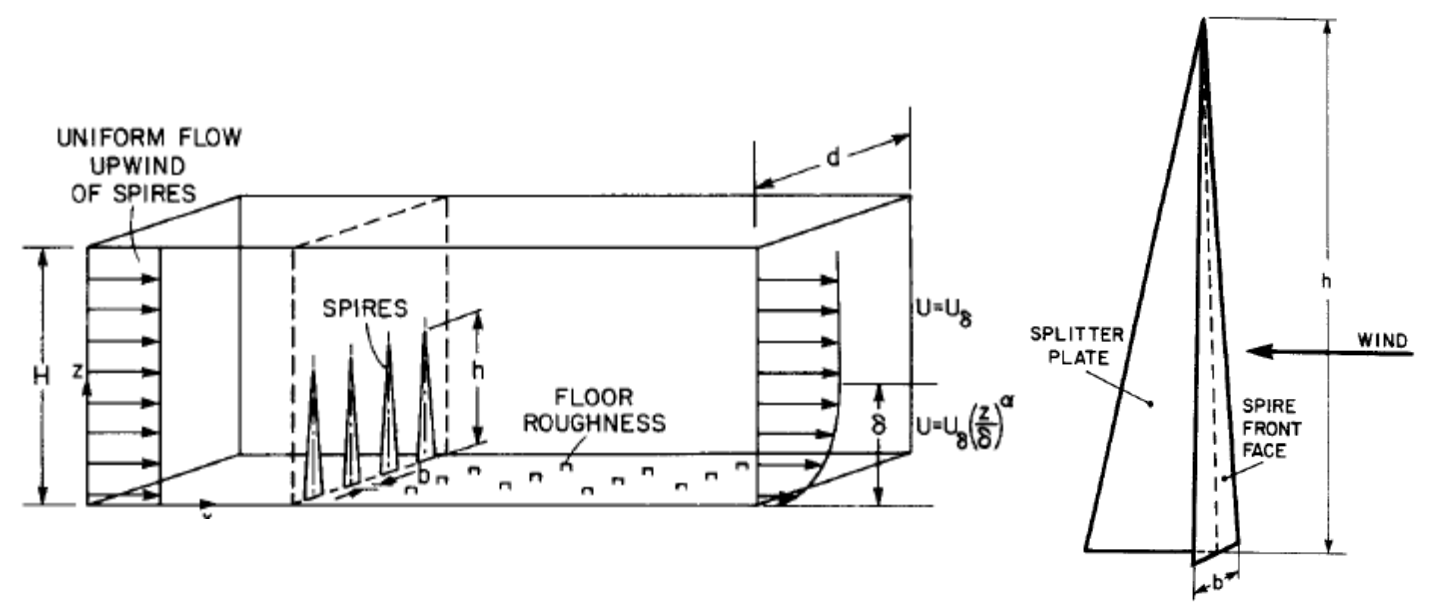

Figure 5. Irwin's (1980) ABL simulating geometry for wind tunnels. Taken from published article with permission from publisher.

First the spire height is computed as a function of $\delta$ (boundary layer height) and $m$ (Hellman exponent). 


$$
h=1.39 \frac{\delta}{1+\frac{m}{2}}
$$

The spire height to base ratio is then computed, with $H$ as the test section height

$$
\frac{b}{h}=0.5\left[\chi * \frac{\left(\frac{H}{\delta}\right)}{1+\chi}\right]\left(1+\frac{m}{2}\right)
$$

with spire parameter 1 solved for:

$$
\chi=\frac{\beta\left\{\left[\frac{2}{1+2 m}\right]+\beta-\left[\frac{1.13 m}{1+m}\left(1+\frac{m}{2}\right)\right]\right\}}{1-\beta^{2}}
$$

along with spire parameter 2:

$$
\beta=\frac{\delta}{H} \frac{m}{1+m}
$$

The ratio of roughness element cube length to boundary layer is solved for with Wooding et al.'s (1973) correlation, with $D$ being the spacing of the squares:

$$
\frac{k}{\delta}=\exp \left[\frac{2}{3} \ln \left(\frac{D}{\delta}\right)-0.1161 \sqrt{\frac{2}{C_{f}}+2.05}\right]
$$

and $C_{f}$ (skin friction coefficient) solved for based on the Hellman exponent using Gartshore's (1973) relation:

$$
C_{f}=0.136\left[\frac{m}{1+m}\right]^{2}
$$

And valid for:

$$
30<\frac{\delta D^{2}}{k^{3}}<2000
$$


Irwin goes on to list the results of 7 separate experiments, showing the resulting Hellman exponent and $\frac{\delta}{H}$ ratio. The experimental spire geometry is listed along with the geometry calculated with the method presented in the paper. There was good agreement between the two, with a maximum difference of $11.2 \%$.

Many researchers cite Irwin for spire geometry generation. Among those are Lopes et al. (2008), who developed an ABL wind tunnel with a test section having dimensions 1.5 $\mathrm{x} 1.5 \times 5 \mathrm{~m}$.
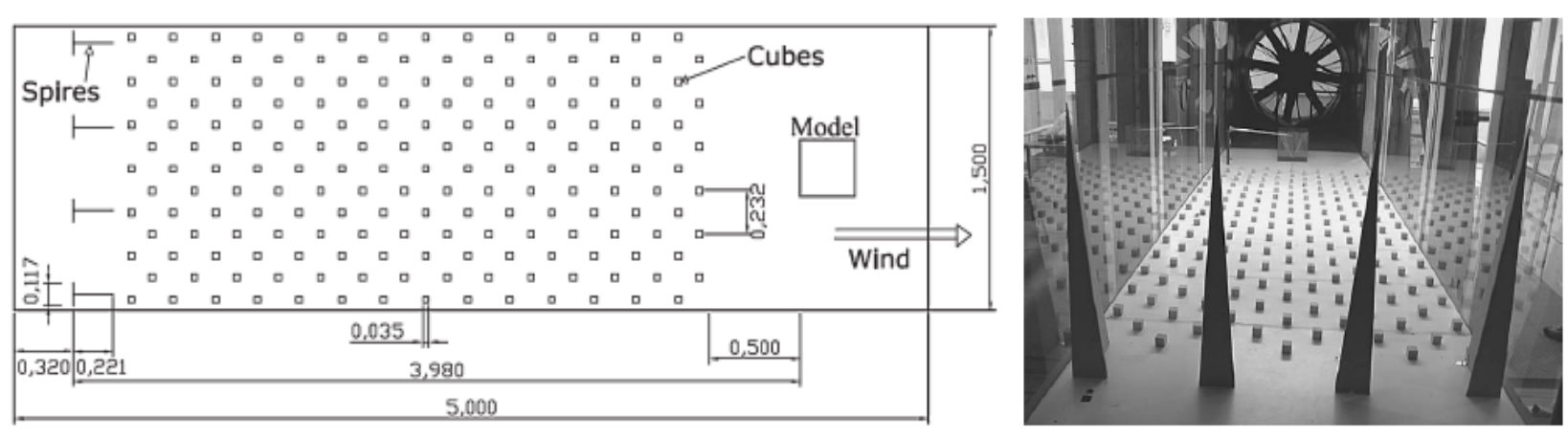

Figure 6. ABL wind tunnel from Lopes et al. (2009). Taken from published article with permission from publisher.

The spire geometry used was directly based on the output from Irwin's formulae, with a targeted Hellman exponent of 0.2 , and a boundary layer height of $0.70 \mathrm{~m}$. The upstream air velocity in the wind tunnel was approximately $10 \mathrm{~m} / \mathrm{s}$. Two hot wire anemometers were calibrated with a manometer, and used to measure the mean velocity profile induced in the wind tunnel. Turbulence was measured using a constant temperature anemometer manufactured by Dantec, with a data acquisition rate of $100 \mathrm{~Hz}$.

They found that they were able to obtain a Hellman exponent of 0.21 (5\% higher than the targeted value) and a boundary layer thickness of $0.765 \mathrm{~m}(9 \%$ higher than the targeted value). 


\section{Objectives}

The importance of alternative energy, both for its economic benefits and for its environmental impact of displacing fossil fuel production, is paramount. The frequency and scale of their implementation depends on being economical. New designs must push the envelope both in system performance and cost.

The purpose of this study was to develop a small scale wind tunnel that simulates the ABL. This would enable researchers to use the countless small scale wind tunnels found in universities. A smaller sized wind tunnel would also allow for smaller sized test specimen, yielding faster design iteration, resulting in more efficient power generation systems. Additionally, the complex flows of an ABL wind tunnel can be used for CFD benchmarking and turbulence model validation.

\section{Chapter Summary}

With increased interest in renewable energy, the field of ABL simulating wind tunnels is likely to grow. The early method of simulating the ABL with roughness elements is not applicable for usage in a small scale wind tunnel, as evidenced by Wieringa (1993), whose empirical relation estimates an extremely long roughness fetch length. The more advanced method of controlled jet grids (Teunissen, 1975) is effective, but requires an excessively complicated experimental apparatus. Lopes et al. (2008) were able to use triangular spires in addition to a roughness fetch to simulate the ABL in a $1.5 \mathrm{x} 1.5 \mathrm{~m}$ cross 
section wind tunnel. The object of this thesis is to show that the success that researchers

have had simulating the ABL using larger wind tunnels can be extended to one of a smaller size. 


\section{METHODOLOGY}

The behavior of the atmospheric boundary layer changes from day to day and from location to location. The objective of this work was to show the viability of small scale wind tunnels, and to develop a methodology for designing passive geometric elements that induce a specific velocity profile in small scale wind tunnels. In the course of this objective, specific geometry was designed to simulate a characteristic boundary layer flow.

\section{Wind Tunnel Velocity Measurements}

Velocity measurements were taken using a pitot static tube connected to a 2 degreeof-freedom traversing system, allowing positioning of the pitot tube in the vertical and longitudinal directions, along the middle of the tunnel. Only the vertical degree of freedom was used in the course of this project. A jackscrew assembly raised and lowered the pitottube, with the height being measured by a ruler placed adjacent to the jackscrew nut. The nut was positioned at its lowest possible height and the pitot tube centerline height was measured off the floor of the wind tunnel, giving its offset.

\section{Velocity measurement calculations.}

Pitot-static tube velocity measurements use a well known manipulation of the Bernoulli equation, in the form of

$$
V_{\text {measured }}=\sqrt{\frac{2 *\left(p_{\text {stagnation }}-p_{\text {static }}\right)}{\rho_{\text {fluid }}}}
$$

The stagnation and static pressure difference is measured by connecting the stagnation tube to the low side of the manomoeter and the static tube to the high side. The 
pressure indicated by the manometer is in inches of water. This is converted into meters of water, multiplied by both the density of water and the gravitational constant, yielding pressure in Pascals.

\section{Pitot-static system validation.}

The pitot-static velocity measurement system was validated using a TSI Model 1129 calibrated velocity jet, used for generating calibration curves for hot-wire probes. The system used an MKS220D pressure transducer to measure the static pressure in a plenum, using a propriatary calibration curve and an internal velocity regulation system. A test fixture was designed and $3 \mathrm{~d}$ printed to fasten the pitot-static tube to a hotwire probe holder.

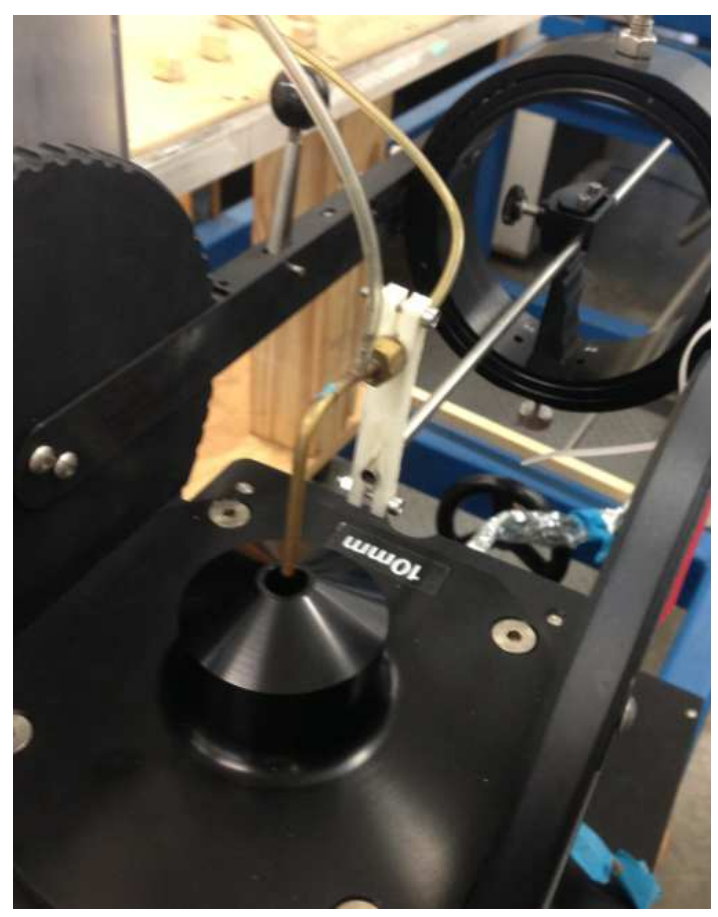

Figure 7. Apparatus for validating pitot-static tube. A calibrated jet was blown onto the pitot-static tube. 
The results are seen in Figure 8. There was close agreement between the calibrator velocity and the measured value. The maximum measured velocity discrepancy was a $4.8 \%$ difference at $10.4 \mathrm{~m} / \mathrm{s}$.

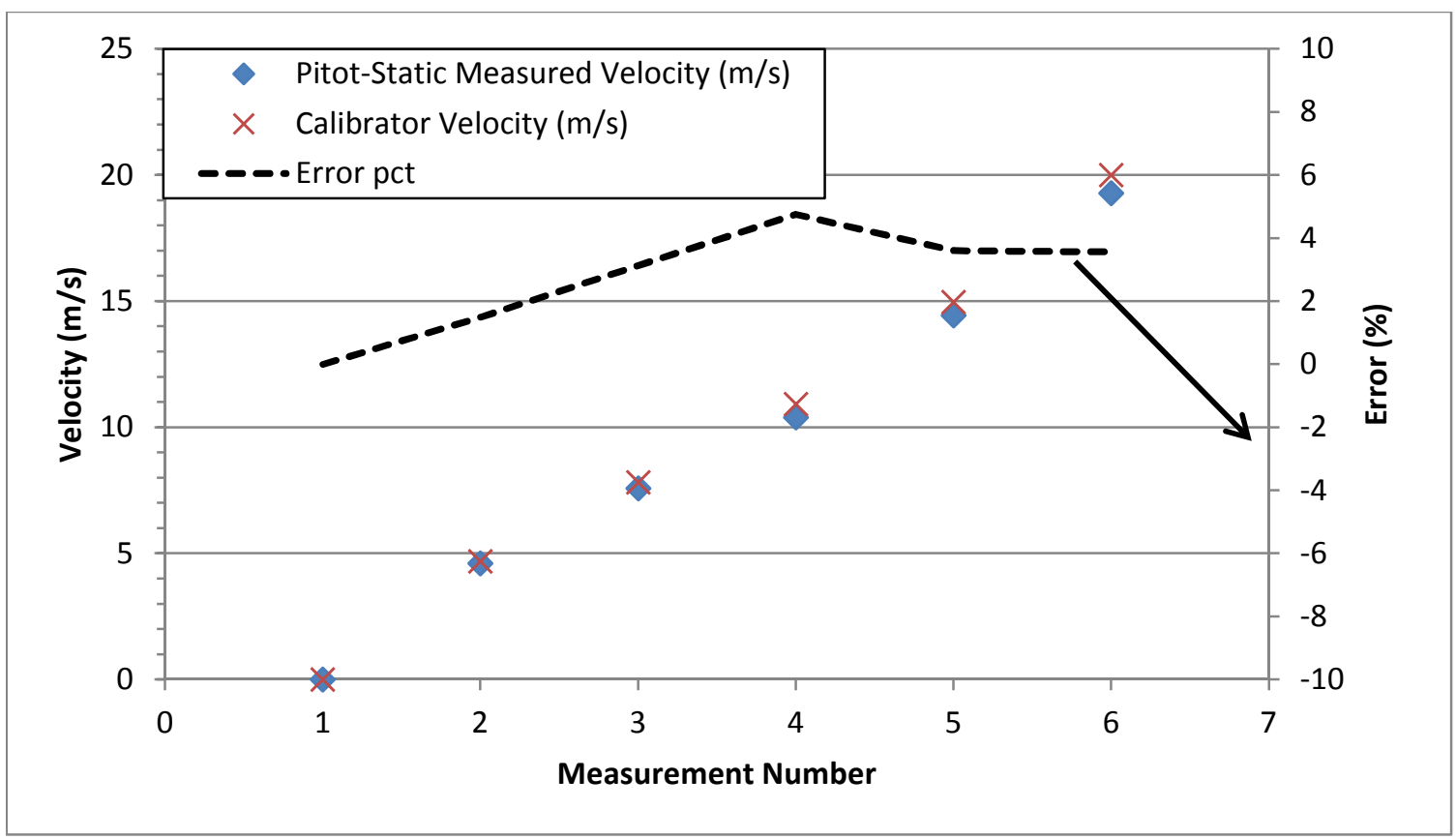

Figure 8. Pitot-static tube validation results.

A calibration curve was considered, but it was thought that the experimental uncertainty for this experiment was probably greater than the measured velocity differential. The jet diameter was only $10 \mathrm{~mm}$, and the exact correct positioning of the tube with respect to the opening was not known, nor was the effect of any misalignment of the tube to the jet centerline. Additionally, slight motion of the pitot tube and holder assembly was visible, perhaps due to fluid interaction with the holder.

\section{Tunnel Flow Simulations}

Numerical simulations were performed in support of wind tunnel development. Several iterations of spire geometry were tested using CFD in lieu of physical testing. 
Quantities that were not measurable using the pitot-static system were evaluated numerically. Additionally, velocities were evaluated using CFD in locations that the pitotstatic system could not reach.

\section{Model setup.}

In each case, Fluent was used to perform the simulations, using a pressure based Navier-Stokes solver with second order formulations for each quantity.

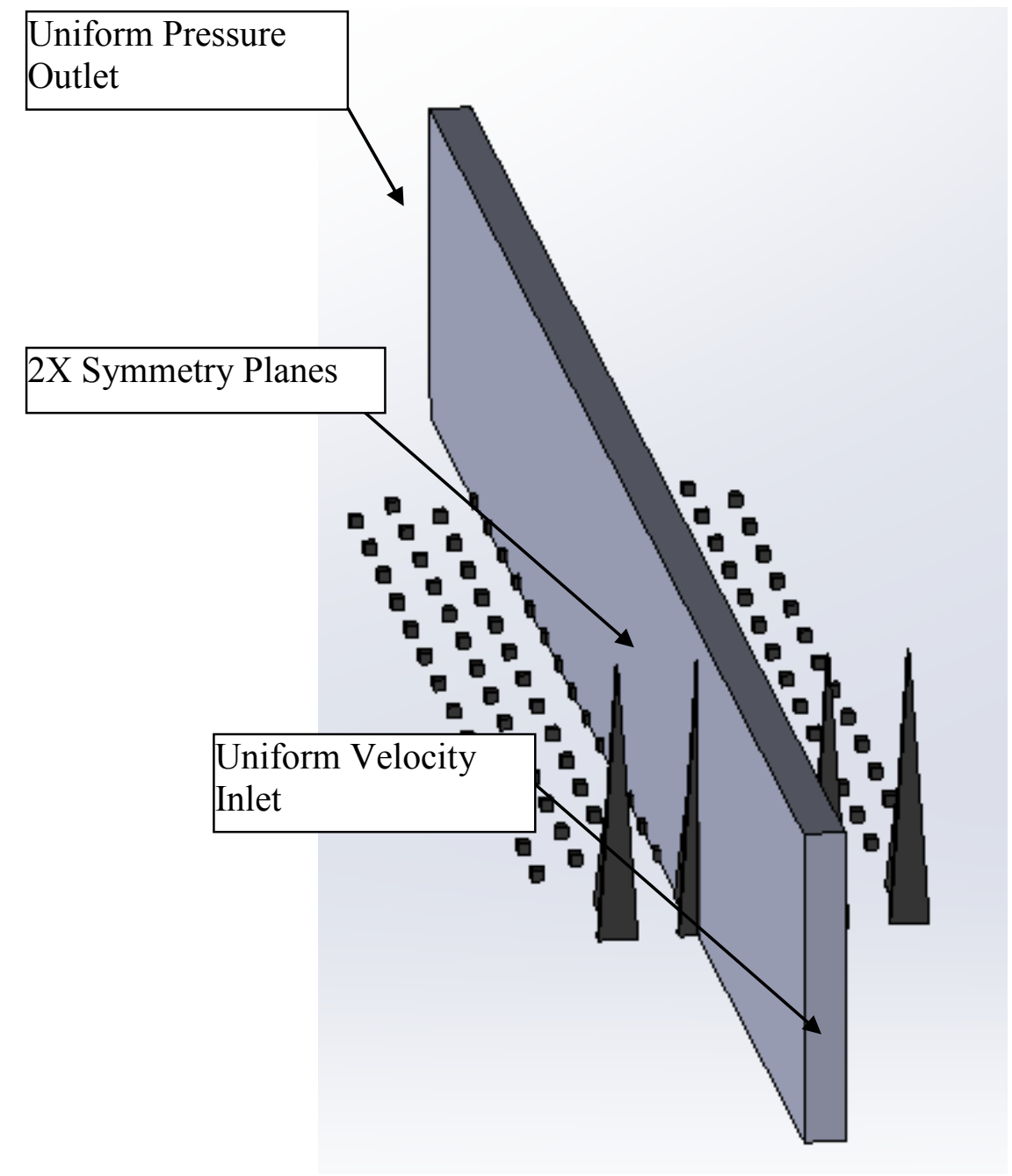

Figure 9. ABL wind tunnel simulation configuration. The computational domain (gray) shows significant problem size reduction using symmetry. 
The computational domain was modeled as $1 / 8$ th the wind tunnel width, with symmetry planes running through the spires and the span between spires. This shrinks the computational domain significantly, but at a cost. Any effect of the side walls is lost. The side walls each generate a boundary layer, which causes a width-wise velocity gradient with a velocity of zero at the walls. The law of conservation of mass indicates that this will cause an increase in velocity in the freestream. Modeling half the width of the tunnel would capture this behavior, but it was thought that it was not worth the computational expense of four times the double-symmetry model.

Inflow was affected by a uniform velocity inlet, upwind of the spire geometry. A uniform velocity was chosen to be about $20 \%$ lower than the desired wind tunnel velocity. A coarse mesh model was then simulated, and the downstream freestream velocity checked. The inlet velocity was then proportionally adjusted to match the desired wind tunnel velocity. The inlet turbulence intensity and turbulent viscosity ratio were set to the program default values of $10 \%$ and 10 , respectively.

\section{Simulation benchmarks.}

The experimental setup investigated by Lopes et al. (2008) was reproduced in a Fluent CFD simulation. The geometry detailed in the paper was modeled in CAD, and the computational domain imported into Fluent. 


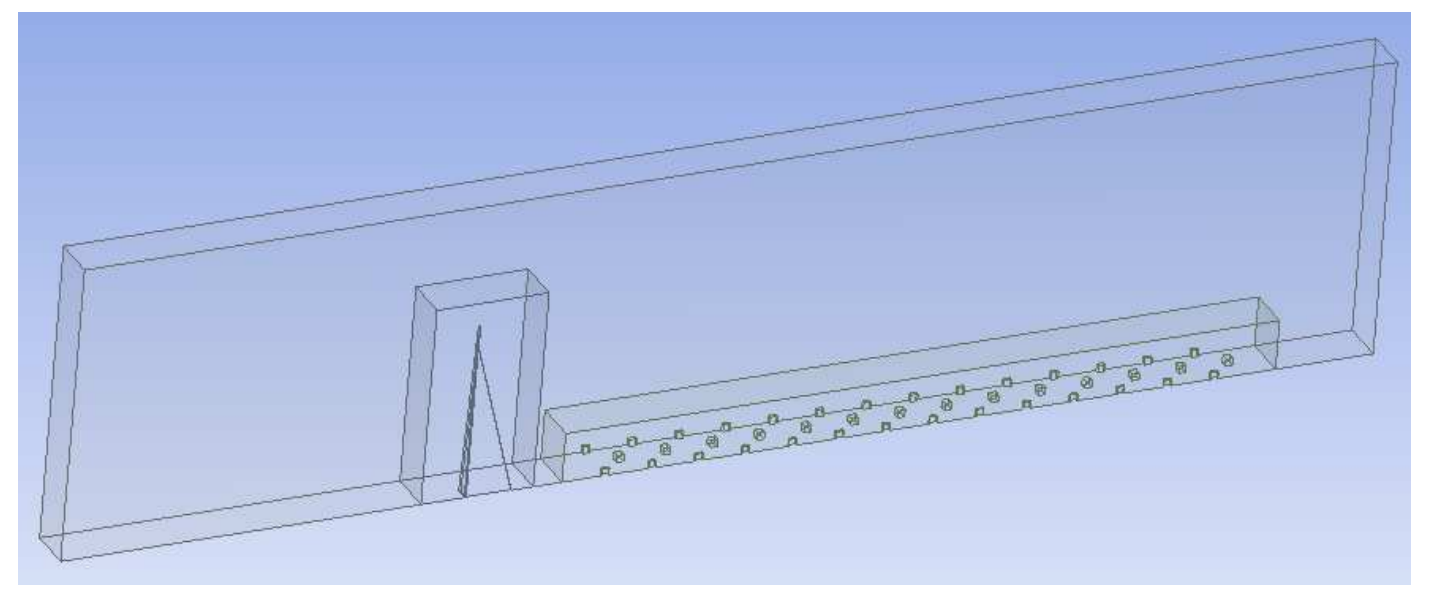

Figure 10. Benchmark analysis computational domain. Numerical reproduction of experiment conducted by Lopes et al. (2008).

The computational domain was meshed using Ansys Mesh. The roughness fetch was meshed with small sized hexahedral elements, with seven elements along each cube edge. The region around the spires was discretized as tetrahedral elements, with prismatic tetrahedrons near the floor of the tunnel. Additionally, prismatic tetrahedrons were used at the tunnel ceiling. The entire domain consisted of a total of 7.2 million cells.
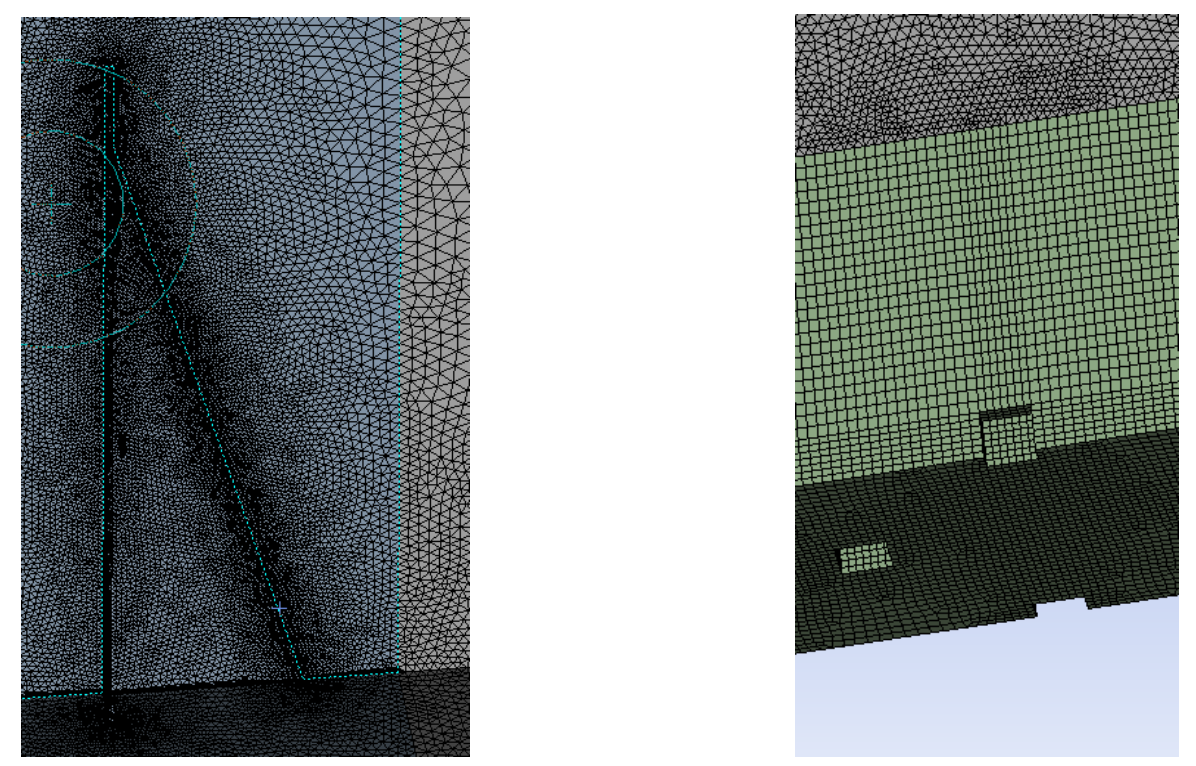

Figure 11. Benchmark analysis mesh details. Close up of spire mesh (left) and roughness fetch mesh (right). Tetrahedral elements were used for the spire and hexahedral for the fetch. 
An SST turbulence model was selected. The solution was initialized using a full multigrid W-cycle for inviscid flow with five mesh levels. The solver was run until the continuity residual was less than 0.004 . The velocities' and turbulence quantities' residuals were all at least one order of magnitude less than 0.001 . The velocity profile was plotted and compared with data graphically extrapolated from the paper detailing the experiment.

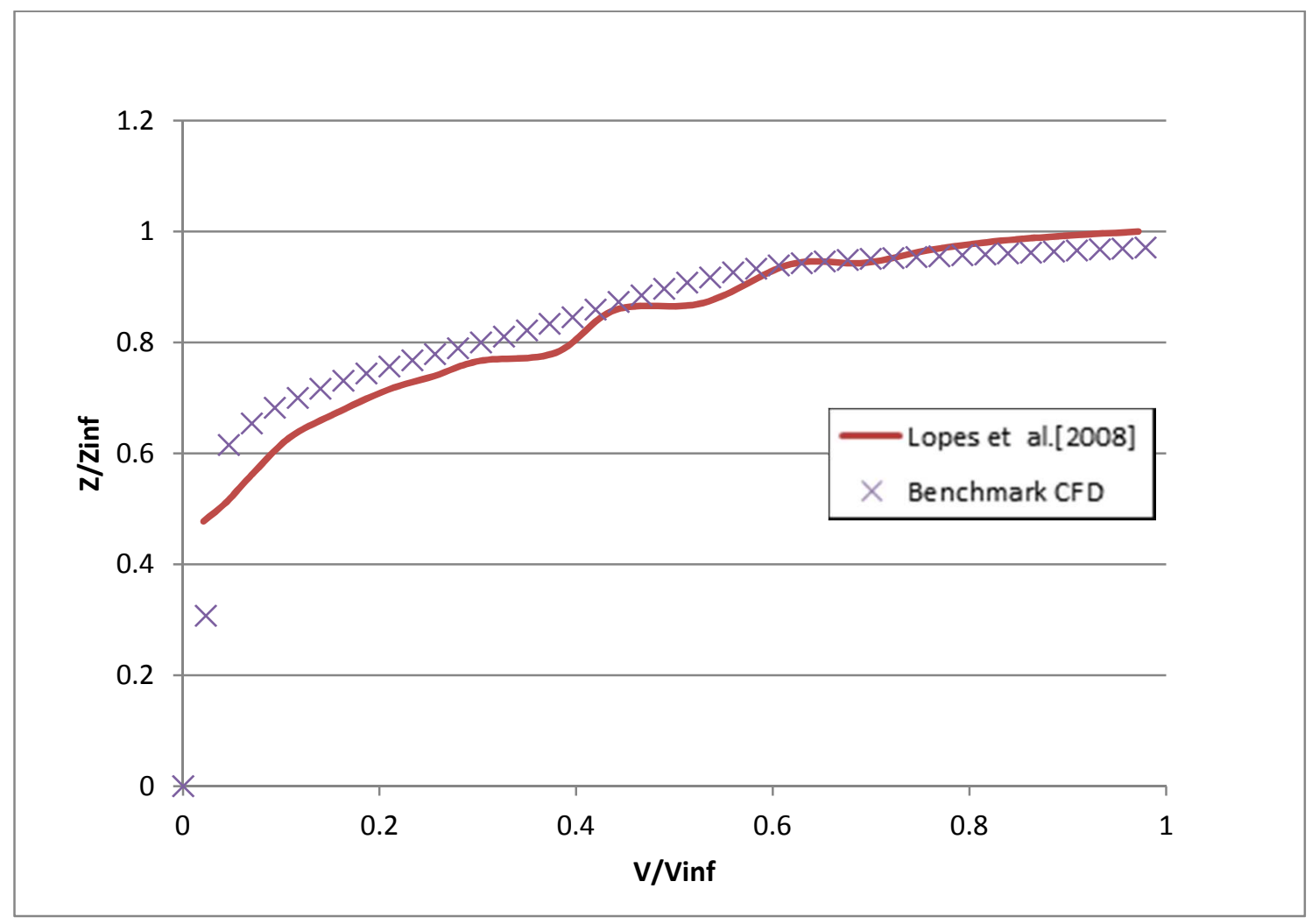

Figure 12. CFD benchmark analysis results comparison.

It can be seen that the CFD simulation had reasonable agreement with the experiment. The maximum velocity profile error was $19 \%$, found near the floor of the tunnel, with the error decreasing with increasing heights. The undulations that occured near the middle of the boundary layer were not resolved by the simulation. Additionally, the turbulence intensity calculated by the simulation was compared with test data and can be seen in Figure 13. 


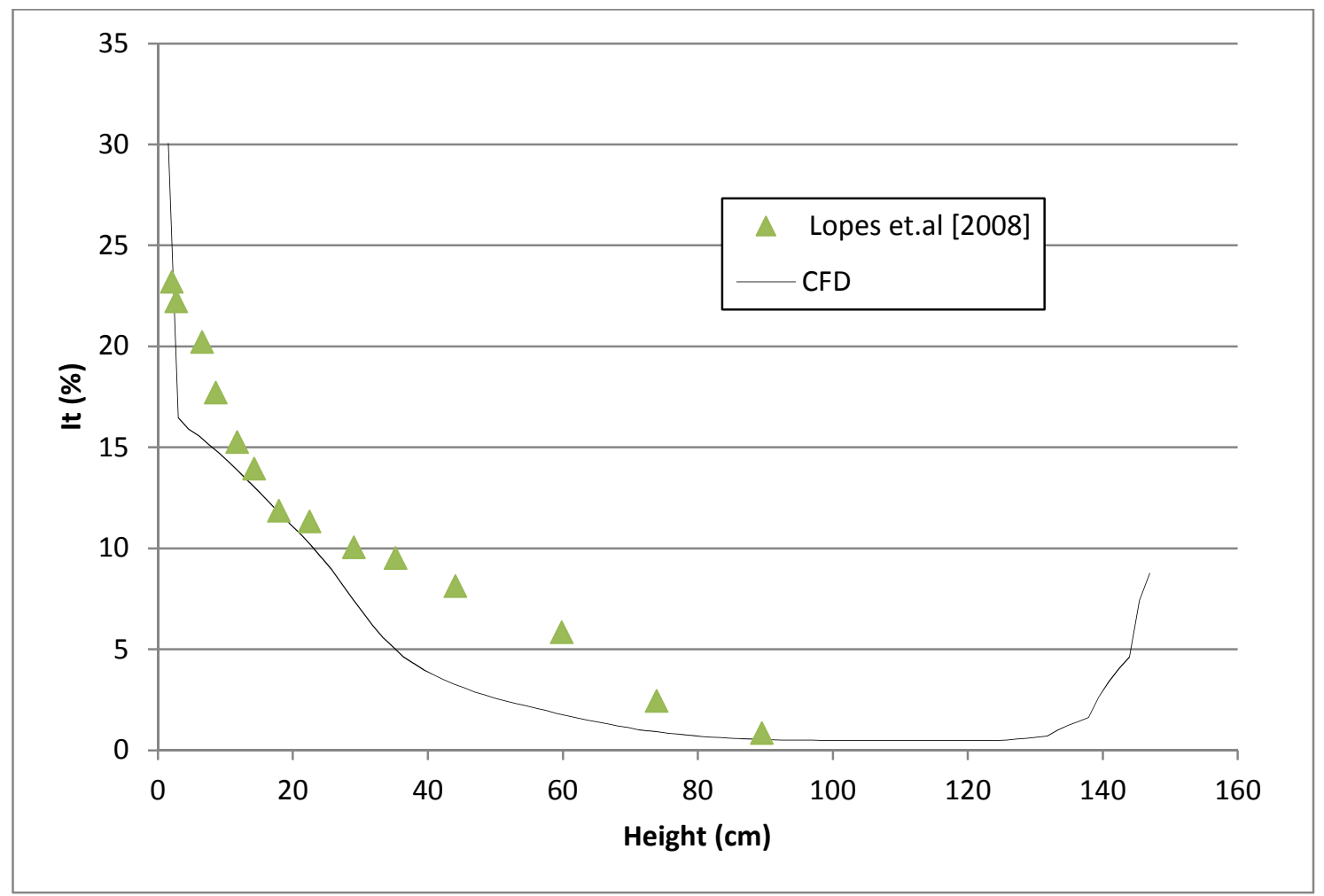

Figure 13. Turbulence intensity profile for CFD simulation and experiment.

It can be seen that there was qualitative agreement between the numerical simulation result and the test data, with turbulence that peaked near the floor and decreased with height. Both results showed a "corner." The experimental result indicated a corner height of $18 \mathrm{~cm}$, while the CFD results indicated a corner height of $36 \mathrm{~cm}$. The quantitative agreement was highly variable, with a maximum error of up to $48 \%$. This comparison showed that CFD simulation, as implemented, could predict velocity profiles reasonably accurately but not turbulence intensity profiles. 


\section{ATMOSPHERIC BOUNDARY LAYER WIND TUNNEL DEVELOPMENT}

The San José State University Mechanical Engineering Department's small size wind tunnel originally had test section dimensions of $1 \times 1 \times 2$ feet. A 3 foot test section extension was constructed and installed onto the wind tunnel. A new frame was constructed to support the inlet in a new location.

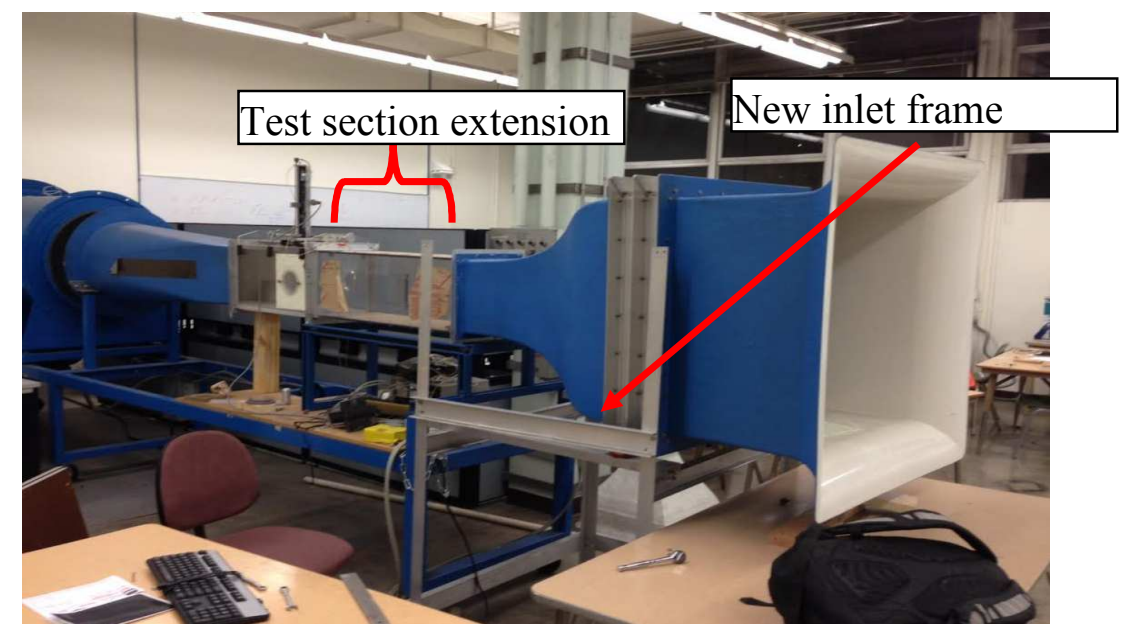

Figure 14. Modified SJSU ME Department wind tunnel. Test section extended 3 feet to yield a 5:1 aspect ratio.

\section{Modified Wind Tunnel Aerodynamics and Small Wind Tunnel Validation}

The passive geometric elements resided on the bottom surface of the tunnel and disrupted the airflow, creating a drastic change in the vertical velocity gradient. This artificially simulated a boundary layer that would otherwise not occur in the wind tunnel. The other surfaces however, also produce velocity gradients via shear flows which are normal to the respective surface. Simulating only the vertical velocity gradient is the objective of most ABL wind tunnel tests. The three naturally formed boundary layers serve to detract from the usable test section envelope; their thicknesses grow along with test 
section length, and this has a greater impact on small size wind tunnels, as a greater proportion of the test area becomes unusable. Increasing the aspect ratio of the tunnel allows for better ABL simulation, but the unwanted boundary layer thicknesses must be checked, such that the inviscid zone (with no geometric elements) is sufficiently large to be useful for testing.

The wind tunnel blower operates at a set speed, and the velocity through the test section of the wind tunnel is modulated by adjusting the distance from the end of the test section to the diffuser. It was found to have a useful freestream velocity range of 6 to 41 $\mathrm{m} / \mathrm{s}$. The Reynolds Number is found by:

$$
R e_{D}=\frac{\rho * U_{\text {freestream }} * D_{h}}{\mu}
$$

resulting in a Reynolds Number range of 116600 to 797000 , indicating turbulent flow over the entire operational range of the wind tunnel. From Zhi-qing (1982), the turbulent hydrodynamic entry length is approximately:

$$
L_{h, \text { turbulent }}=1.359 * D_{h} * R e_{D}^{\frac{1}{4}}
$$

which yields an entry length of 7.65 meters in the case of a $6 \mathrm{~m} / \mathrm{s}$ freestream velocity, being approximately 5 times the test section length. It was thought that the boundary layer development for each of the three surfaces was analogous to flow over a flat plate, in which case the Reynolds Number is

$$
R e_{x}^{\frac{1}{5}}=\frac{\rho * U_{\text {freestream }} * x}{\mu}
$$


The transition to turbulence is known to occur at a Reynolds Number approximately equal to 500,000 . The boundary layer thicknesses for laminar and turbulent flows over flat plates are approximately:

$$
\begin{gathered}
\delta_{\text {laminar }}=5 * \frac{x}{\sqrt{R e_{x}}} \\
\delta_{\text {turbulent }}=0.38 * \frac{x}{R e_{x}^{1 / 5}}
\end{gathered}
$$

The boundary layer thickness can then be plotted along the length of the test section. For a freestream velocity of $41 \mathrm{~m} / \mathrm{s}$ :

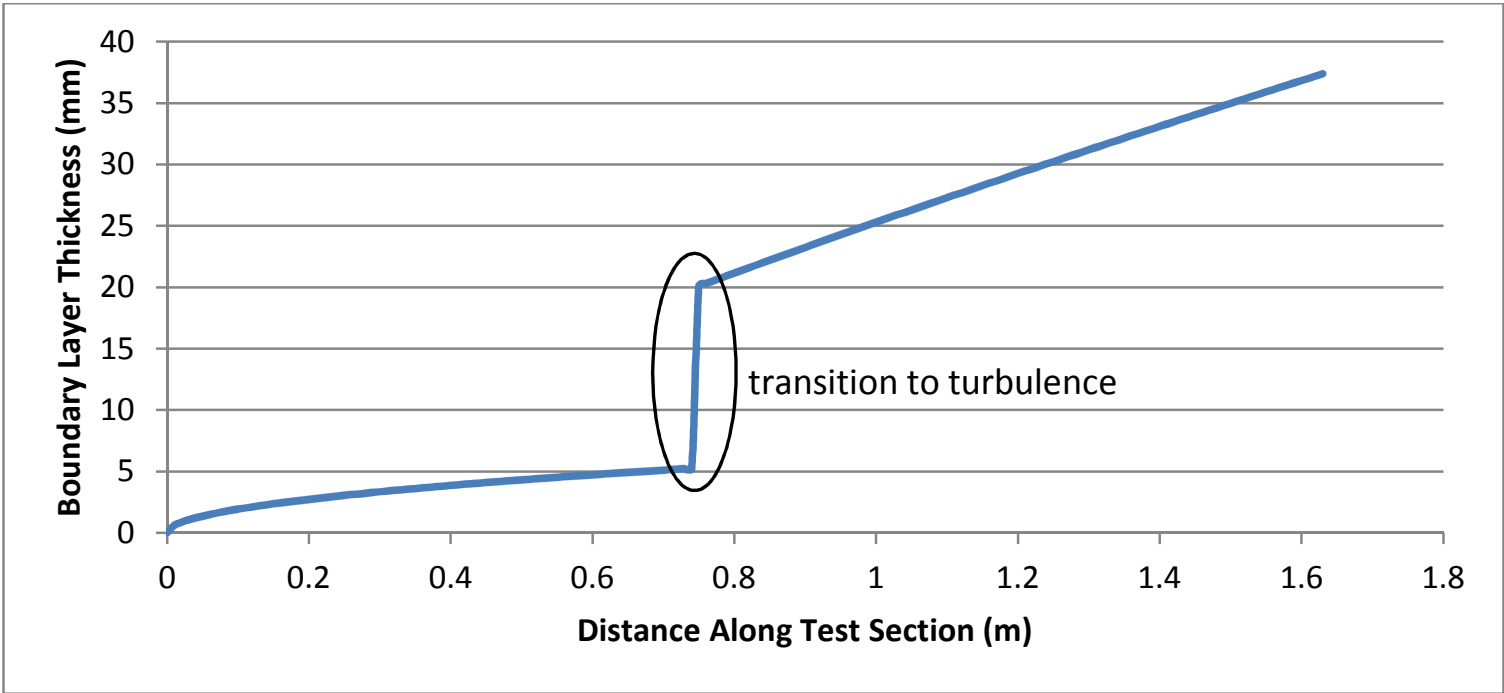

Figure 15. Boundary layer thickness growth. Growth along wind tunnel walls for a freestream velocity of $41 \mathrm{~m} / \mathrm{s}$. Assumes applicability of flat plate solution.

It can be seen that at a test section location of $1.5 \mathrm{~m}$ from the inlet, a boundary layer thickness of $27 \mathrm{~mm}$ was expected. This would have resulted in a horizontal useful test area truncation of $54 \mathrm{~mm}$ or $17.7 \%$ of the horizontal length, and a $27 \mathrm{~mm}$ or $8.9 \%$ of the vertical length. This would leave a useful test area of $25.1 \times 27.7 \mathrm{~cm}$, which was determined to be acceptable. 
Where the assumption of flat plate boundary layers fails is at the corner where two orthogonal sides meet. It was thought that the effect of the corner should be quantified. This is impossible with the existing experimental apparatus, as the pitot-tube travel assembly only has two degrees of freedom: vertical and longitudinal in the center plane of the wind tunnel.

A CFD study was performed to quantify the corner effect, and was validated with experimental measurements at locations that the traverse system could reach. The bare wind tunnel was modeled as a $45^{\circ}$ slice of one quarter of the wind tunnel, with symmetry planes on the vertical and diagonal sides. This was the smallest domain possible without losing any physical fidelity. The wind tunnel inlet was not modeled, and the inflow was assumed to have a uniform velocity: it was assumed that the inlet was designed in such a way that it provides undisturbed flow to the tunnel. A k-e turbulence model was used using standard wall functions.

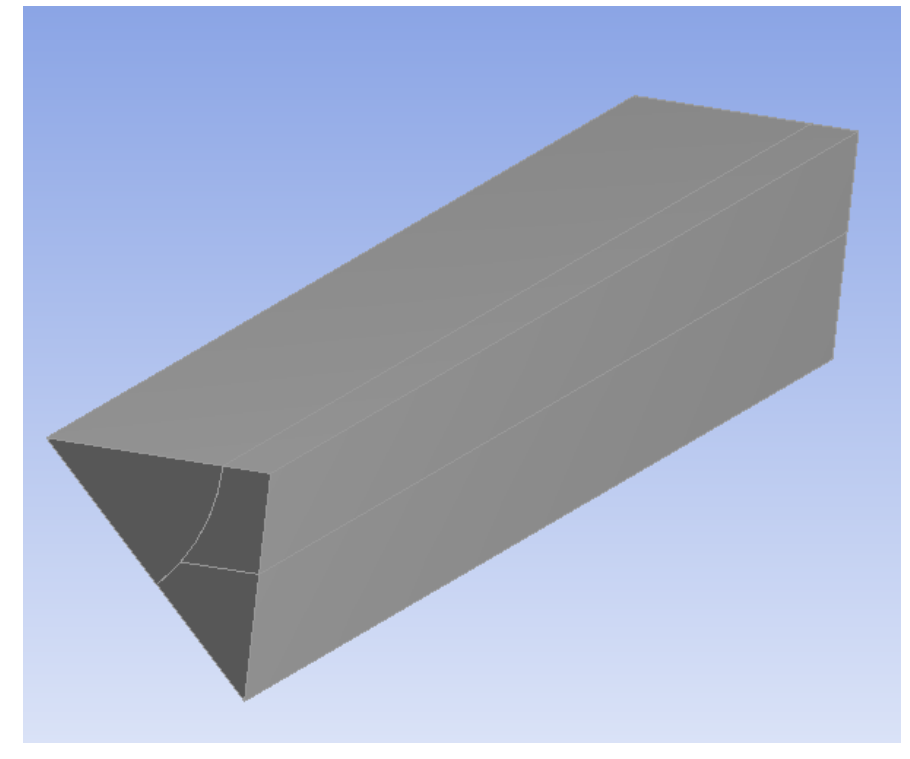

Figure 16. Corner-effect quantification simulation computational domain. Two symmetry planes were implemented to reduce the computational domain to a $45^{\circ}$ wedge. 


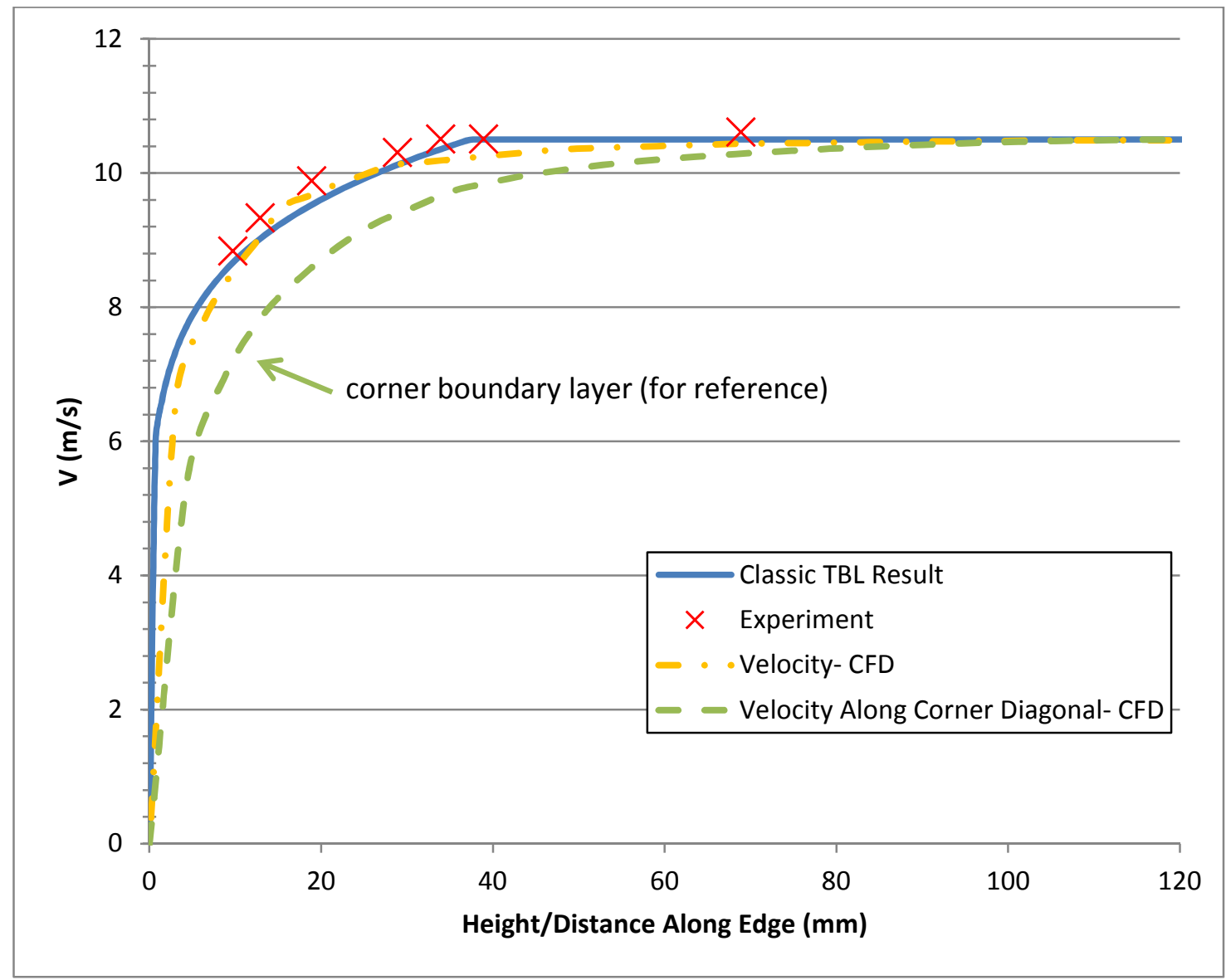

Figure 17. Comparison with flat plate theory. Excellent agreement found between theory, experiment, and numerical simulation.

It was that there was excellent agreement between the empirical flat plate solution, the CFD simulation, and the experimental values. There was a maximum error of $8.5 \%$ between the CFD computed velocity and the measurement. Additionally, the thickness of the corner boundary layer was $83 \mathrm{~mm}$, more than double that of the vertical/horizontal wall boundary layers. 

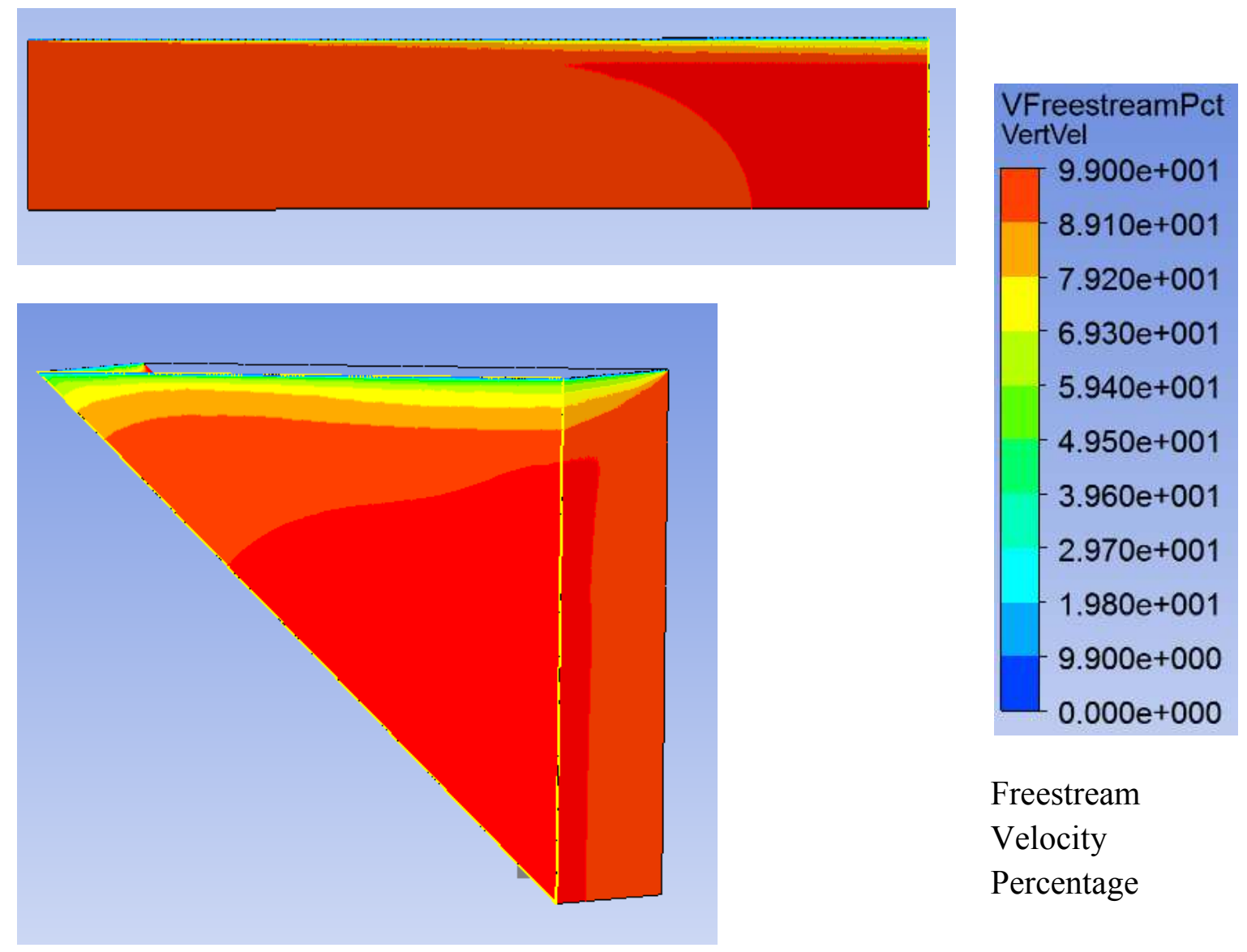

Freestream

Velocity

Percentage

Figure 18. CFD velocity results. Boundary layer growth on vertical wall (top); Test section outlet freestream velocity percentage (lower left). Red contour indicates $99 \%$ freestream velocity.

The boundary layers generated by the tunnel's two sides and ceiling produced a test area truncation of $7.5 \mathrm{~cm}$ of width, $3.75 \mathrm{~cm}$ of height, and $8.3 \mathrm{~cm}$ of the diagonal. This resulted in a usable test section shown in Figure 19. 


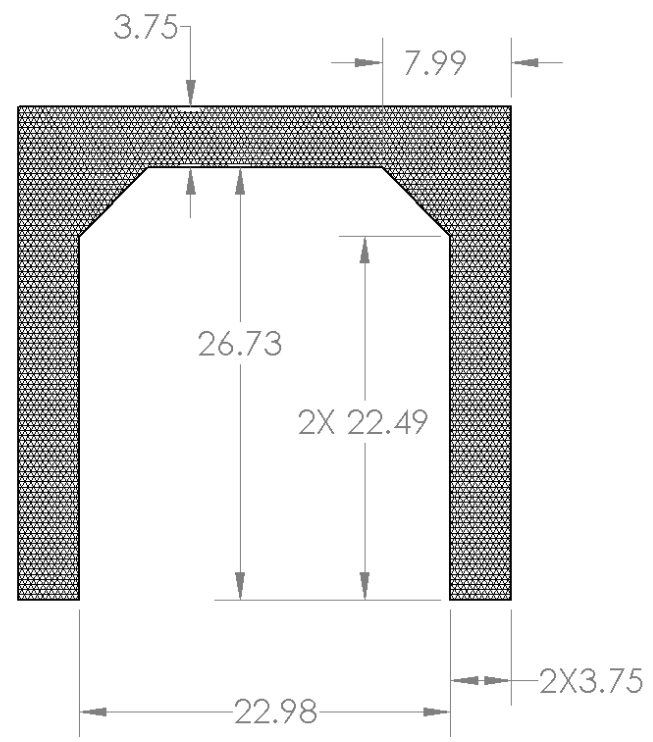

Figure 19. Expected usable test section. Truncated portion hashed.

Despite a $35.8 \%$ reduction in test area, there was still sufficient space for test specimens, showing that the natural boundary layers of a wind tunnel with dimensions of $30.5 \mathrm{~cm} \times 30.5 \mathrm{~cm} \times 1.6 \mathrm{~m}$ would not preclude its usage from ABL simulation.

\section{Roughness fetch development.}

The roughness fetch consisted of an array of cubic roughness elements. A side dimension of 0.4375 inches was chosen, as it fit into the guidelines set by Irwin (1982), and was a common fractional inch dimension (7/16). The cubes were constructed from square cross section wood stock of the same side dimensions, with each cube requiring one measured cut to produce the final shape. The fetch was constructed by gluing the cubes onto a fiberboard sheet with spacing of approximately $4 \mathrm{~cm}$ in a semi-random pattern as seen in Figure 20. 


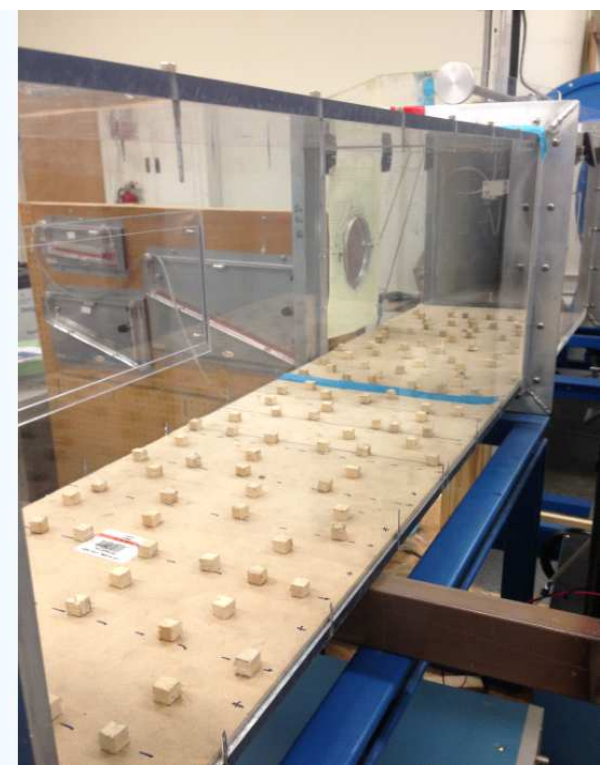

Figure 20. Roughness fetch installed in wind tunnel.

The roughness fetch was installed into the tunnel, and secured with bolts to the bottom surface. A velocity profile was measured and can be seen in Figure 21.

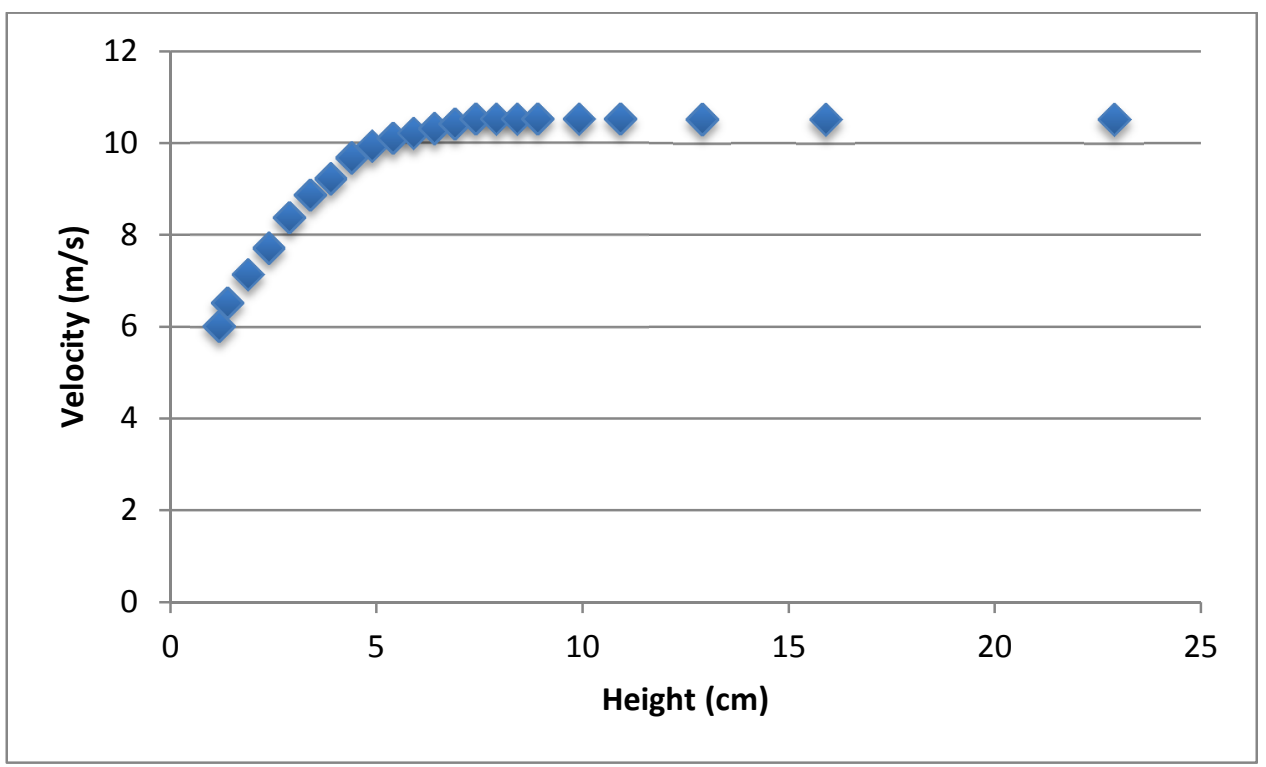

Figure 21. Roughness fetch velocity data.

It was found that the boundary layer height resulting from the roughness fetch was $7.20 \mathrm{~cm}$, compared to $3.75 \mathrm{~cm}$ for the plain tunnel configuration (Figure 17), with the 
freestream velocities being approximately the same. It is interesting to note that plugging in the measured boundary layer thickness and the size of the roughness elements employed into Wieringa's (1993) empirical relation (Eq. 9), one finds a required fetch length of 4.572 $\mathrm{m}$, compared to the actual length of $1.4 \mathrm{~m}$. While this is the same order of magnitude, it is still more than three times larger, leading to doubt as to the validity of Equation 9 for smaller fetch lengths. For completeness, the roughness fetch velocity profile was matched to the power law profile seen in Figure 22.

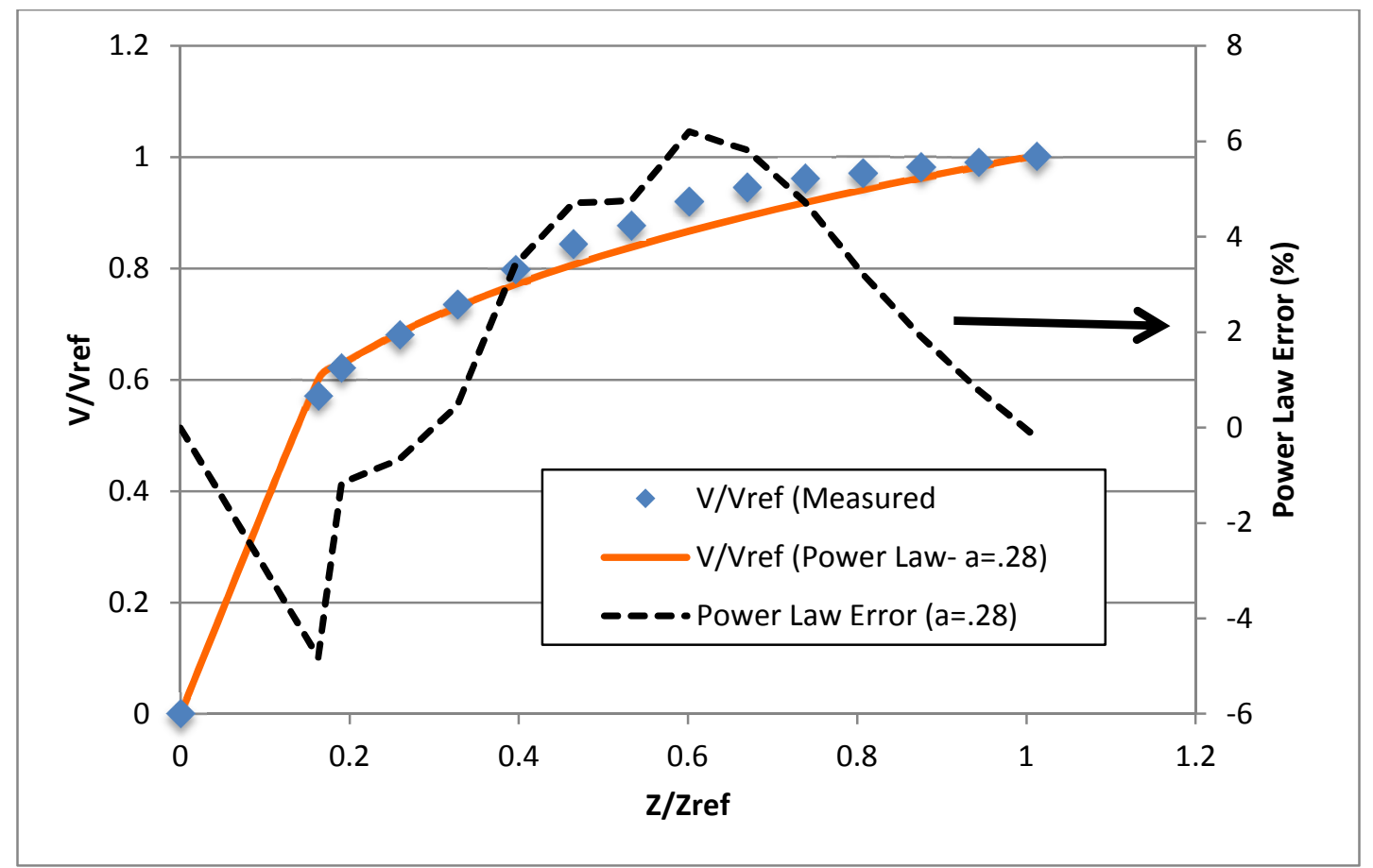

Figure 22. Velocity Profile for Roughness Fetch. A power law with $\alpha=$ 0.28 is simulated with reasonable agreement.

It can be seen that the roughness fetch produced a velocity gradient with reasonable agreement with an $\alpha=0.28$ power law profile, with a maximum error of $6 \%$. The obvious deficiency was a boundary layer height of $7 \mathrm{~cm}$, limiting the applicability. However, there 
are some cases where this low boundary layer height might be useful. Nocturnal boundary layers routinely have altitudes of $100 \mathrm{~m}$ or less. The wind tunnel configuration could be used to simulate a tall structure interacting with a nocturnal boundary layer in a coastal environment ( $\alpha=0.28$ ), with part of the structure extending beyond the boundary layer, exposed to the freestream velocity.

\section{Generation of Spire Geometry}

A combination of cubic roughness elements and spires was used to manipulate the wind tunnel velocity profile. This configuration was chosen as other researchers have had success with similar methods using larger wind tunnels.

\section{Characteristics of the simulated boundary layer.}

It was decided to simulate a boundary layer with a power law exponent value of 0.2 . This is representative of a neutrally stable boundary layer in a rural environment, an important case for wind power applications.

\section{First spire design: based on literature}

Geometry based on Irwin's (1981) relations was generated for use in the SJSU wind tunnel, based on the desired velocity profile, and can be seen in Figure 23. 


\begin{tabular}{|c|c|}
\hline $\begin{array}{c}\text { Geometric } \\
\text { Parameter }\end{array}$ & Value \\
\hline $\boldsymbol{\delta}(\boldsymbol{i n})$ & 8.34 \\
\hline $\boldsymbol{h}(\boldsymbol{i n})$ & 10.596 \\
\hline $\boldsymbol{b}(\boldsymbol{i n})$ & 1.467 \\
\hline $\boldsymbol{k}(\boldsymbol{i n})$ & $\begin{array}{c}0.4375 \\
(7 / 16)\end{array}$ \\
\hline $\boldsymbol{D}(\boldsymbol{i n})$ & 3.225 \\
\hline
\end{tabular}

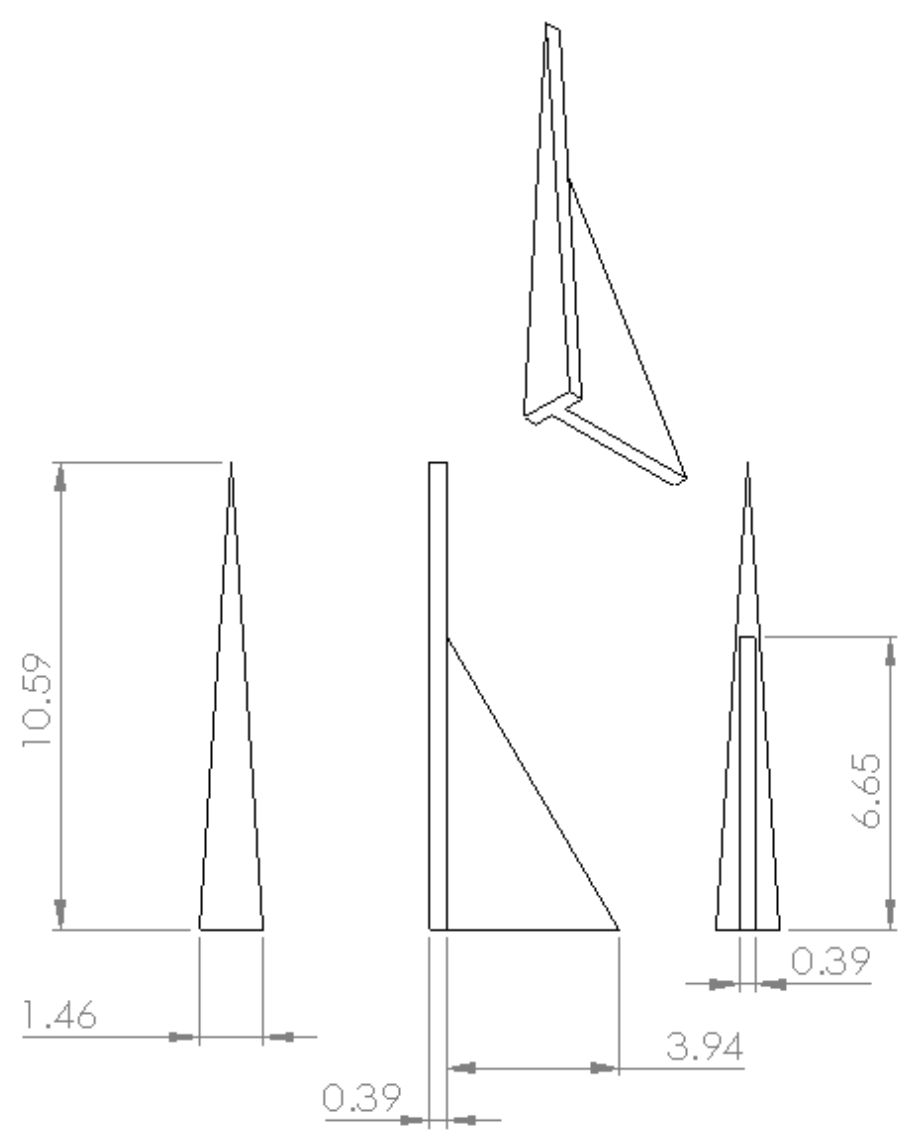

Figure 23. First iteration of ABL simulation geometry. Parameters calculated from Irwin's (1981) guidelines. Dimensions in inches.

The calculated spire geometry was used to create a 3D model. This model was then 3D-printed using Fused Deposition Modeling in ABS plastic. Initially, this was attempted as one single printed piece. This resulted in the part detaching from the build table, becoming ruined. Success was found in printing the spires as a series of flat triangles. This added to the build and set-up time as the triangles had to be glued together. 


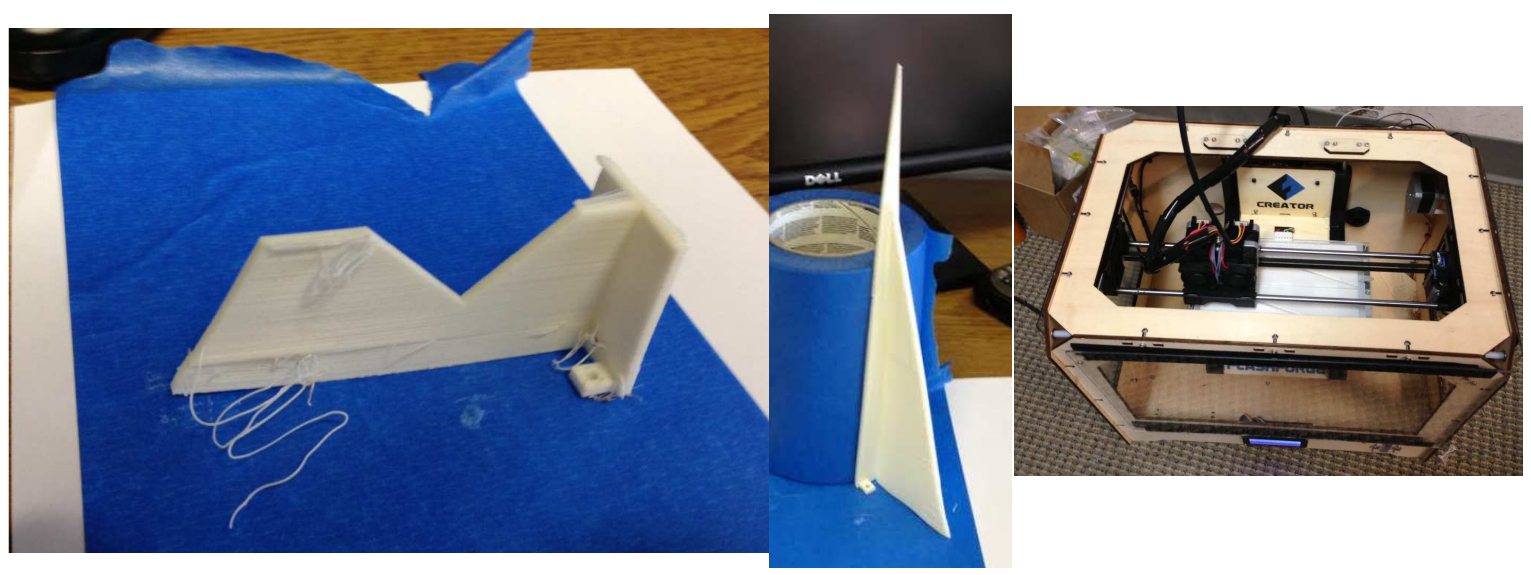

Figure 24. 3D printed spire construction. Initial difficulties (left). Final product (center). ABS FDM process used (right).

A metal plate was constructed with a slot for bolting the spires to such that their position could be adjusted. The spires were positioned symmetrically with a center to center distance of 3.0 inches.

The roughness fetch and spire assembly was secured to the wind tunnel using bolts. With the blower engaged, the diffuser opening length was adjusted to yield a freestream velocity of approximately $10 \mathrm{~m} / \mathrm{s}$. Velocity versus height measurements were taken at the end of the test section with the pitot tube traverse assembly.

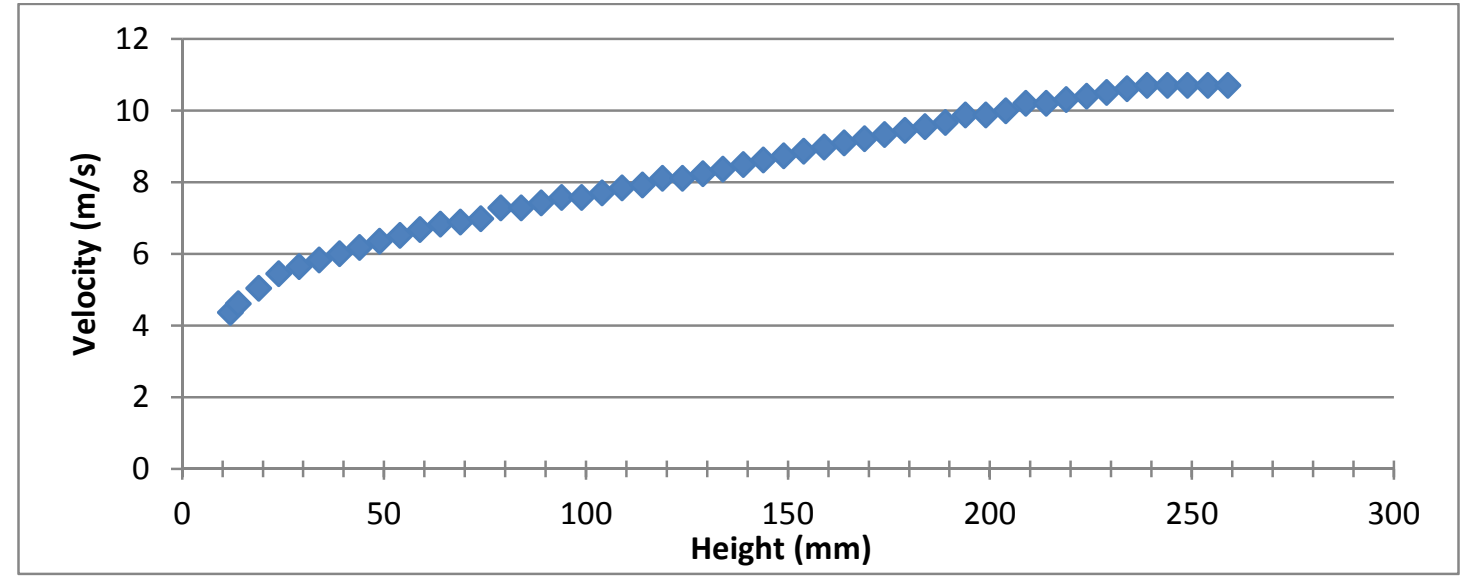

Figure 25. Measured velocity data for first iteration of geometry. 
A number of interesting characteristics were observed in the velocity plot (Figure 25). A boundary layer with a height of $23.4 \mathrm{~cm}$ was generated.

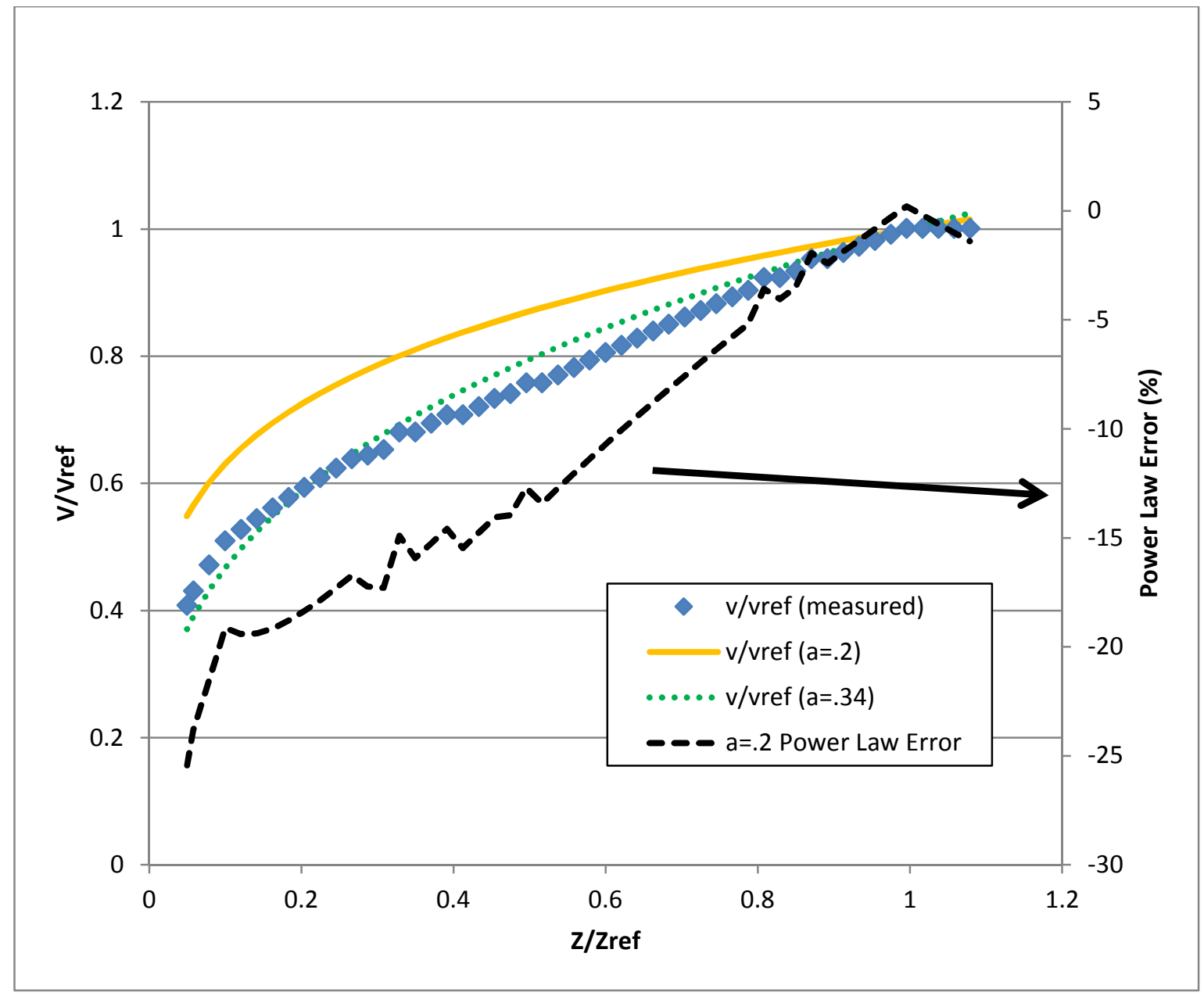

Figure 26. Measured velocity profile for first iteration of geometry. Poor agreement with the desired power law profile ( $\alpha=0.20$, in yellow). Thicker boundary layer $(\alpha=0.34)$ plotted in green for reference.

It can be seen that the velocity profile generated by the first iteration of geometry inadequately simulated the desired boundary layer. The maximum error was found to be $26 \%$, and the average error magnitude was $12.2 \%$. 
It was unclear as to why the geometry generated by Irwin's empirical relations so ineffectively simulates the boundary layer of interest. It was possible that the mechanism was related to the smaller size of the wind tunnel being investigated.

\section{Geometry Adaption Algorithm}

Because of the poor adherence of the empirically derived geometry's velocity profile to the desired power law velocity profile, a method was devised to generate geometry with better adherence. The output of the empirical relations is simple, triangular shaped spire with straight profile edges. This makes the shapes easy to produce and catalog design data, a necessity during their initial development in the 1960s and 1970s. However, today we have commercial CAD packages that allow users to design complex 2D and 3D shapes. Additive manufacturing enables going directly from those complex cad models to physical specimens. To take advantage of these advances, an algorithm was developed to produce nonlinear spire geometry.

An existing spire arrangement is defined by the spacing $L$ of the spires and a function $x(z)$, which defines the horizontal distance between the spire's edge to its midplane. A non-dimensional geometric parameter was defined by

$$
\Psi(z)=\frac{\frac{L}{2}-x(z)}{\frac{L}{2}}
$$

which was representative of the ratio of open space at height $\mathrm{z}$ in the flow channel between spires. 

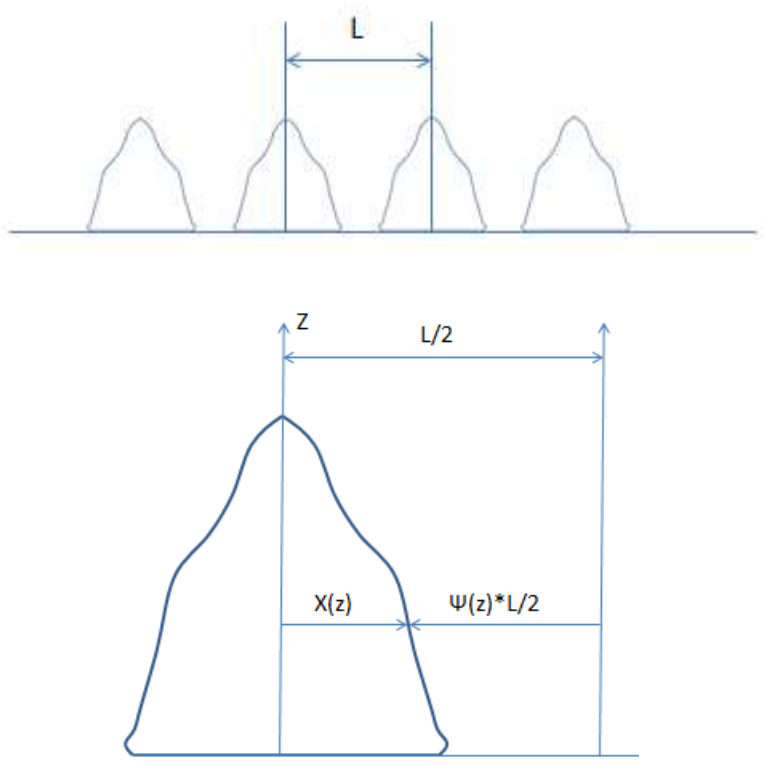

Figure 27. Geometric parameters of spire array. Algorithm solves for $\Psi(z)$.

The spire array and roughness fetch yield a specific nondimensional velocity profile $V / V_{\text {ref }}(z)$ when placed in a wind tunnel flow, which can be measured by experiment or found using numerical simulation.

The velocity profile was assumed to be a sum of the contributions of a roughness cube function and spire function, $C\left(\frac{z}{z_{r e f, C}}\right)$ and $S\left(\frac{z}{z_{r e f}}\right)$, respectively:

$$
\frac{V}{V_{\text {ref }}}(z)=C(z)+S(z)
$$

The cube function was assumed to be unaffected by the spire geometry, and can be found using curve fitting on test data from Figure 22.

$$
\begin{gathered}
C(z)=0.035 *\left(\frac{z}{z_{\text {ref,C }}}\right)^{-1.492} \\
\text { with } Z_{\text {ref }}, c=6.6 \mathrm{~cm}
\end{gathered}
$$


The spire function was taken as the product between nondimensional geometry function $\Psi(z)$ and a transfer function $\Phi(z)$, which related $\Psi$ to the measured velocity profile

$$
S(z)=\Psi(z) * \Phi(z)
$$

Combining equations 22,23 , and 24 , and solving for the transfer function

$$
\Phi(z)=\frac{\left(\frac{V}{V r e f}(z)-0.035 *\left(\frac{z}{z_{r e f, C}}\right)^{-1.492}\right)}{\Psi(z)}
$$

Alternatively, solving for the measured velocity profile

$$
\frac{V}{\text { Vref }}(z)=\Psi(z) * \Phi(z)-0.035 *\left(\frac{z}{z_{r e f, C}}\right)^{-1.492}
$$

An error function is needed, to quantify the discrepancy between the performance of the geometry and the desired velocity profile. It is defined as

$$
E(z)=\frac{V}{V r e f}(z)-\left(\frac{z}{z_{\text {ref }}}\right)^{a_{\text {desired }}}
$$

A new spire profile can now be generated. Setting $\boldsymbol{E}(\mathbf{z})=\mathbf{0}$, substituting Equation 27, and solving for an updated dimensionless geometry function:

$$
\Psi_{\text {update }}(z)=\frac{\left(\frac{z}{z_{r e f}}\right)^{a_{\text {desired }}}+0.035 *\left(\frac{z}{z_{r e f, C}}\right)^{-1.492}}{\Phi(z)}
$$

The updated geometry function outputs the spire geometry that will produce an error free velocity profile. This is assuming that the transfer function will not change between iterated shapes. This is surely not the case. There is no doubt that the transfer 
function will be highly nonlinear, as is the case for complex fluid flows. A new shape function is introduced:

$$
\Psi_{\text {new }}(z)=\omega * \Psi_{\text {old }}(z)+(1-\omega) \Psi_{\text {update }}(z)
$$

with $\omega$ being a shape-update relaxation factor between 0 and 1 .

This serves to limit how aggressively the shape is updated between iterations, with the aim of minimizing the change in the transfer function. A detailed study was not performed to determine the best value for $\omega$. A value of 0.5 was thought to be reasonable and was used. The linear dimension $x_{\text {new }}(z)$ can be solved for by rearranging Equation 22:

$$
x_{\text {new }}=\frac{L}{2}-\Psi_{\text {new }}(z) * \frac{L}{2}
$$

\section{Spire Designs Two and Three}

The second iteration of spire geometry was generated using the proposed algorithm. All calculations and manipulations were performed using spreadsheet software. The transfer function was calculated and plotted in Figure 28. 


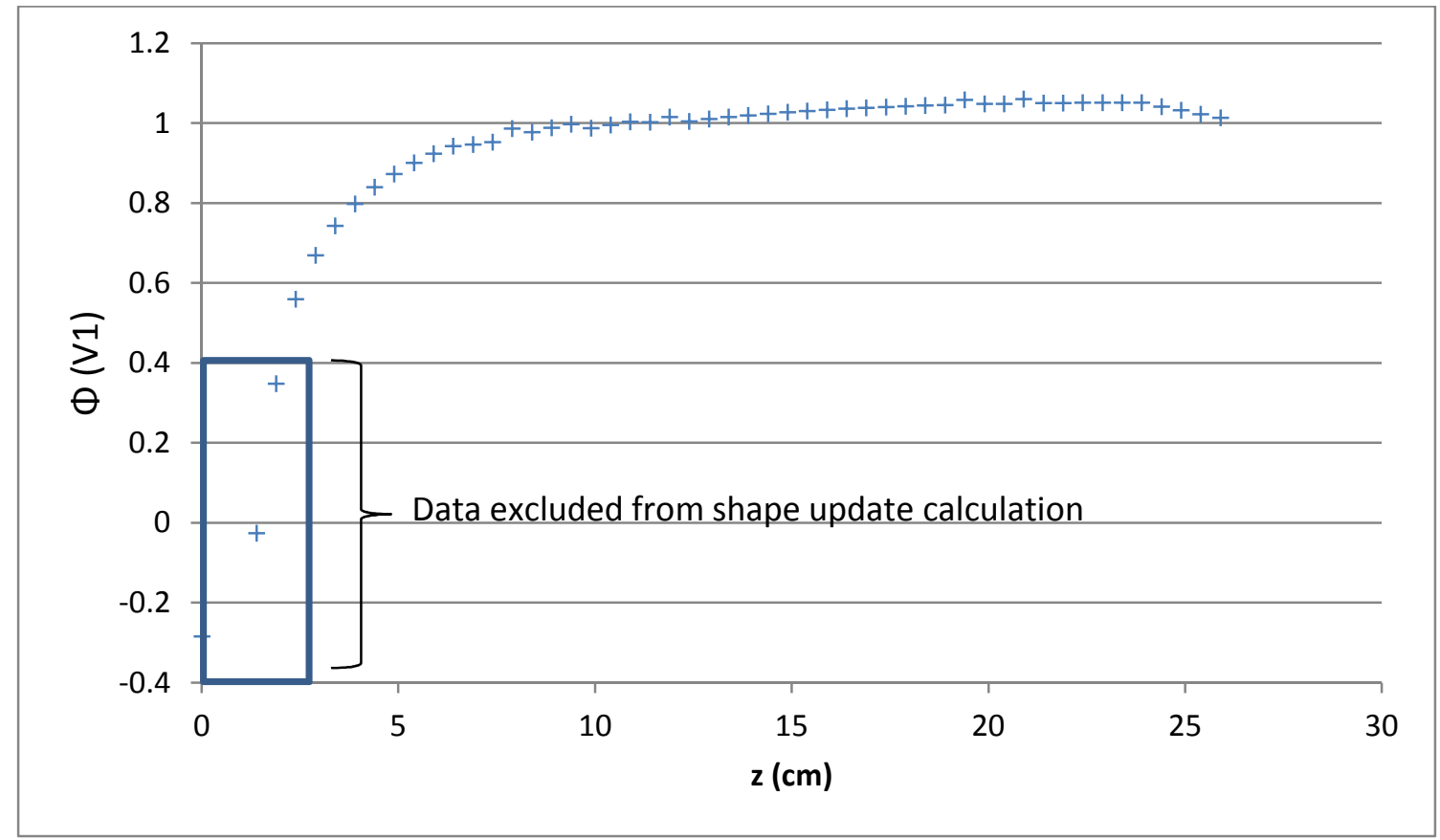

Figure 28. Calculated transfer function for first iteration of geometry. Points with a value of less than 0.6 were excluded from shape function calculation.

The transfer function was used to calculate an updated spire shape, seen in Figure 29. It was thought that the several lowest points made for an awkward shape. It was found that by neglecting geometric points with transfer function values less than 0.6 (roughly the lower $10 \%$ of the spire height), the shape looked reasonable. To fill in the lower $10 \%$, a $5^{\text {th }}$ order polynomial was used to capture the geometric trend and extend it to $\mathrm{z}=0$. 


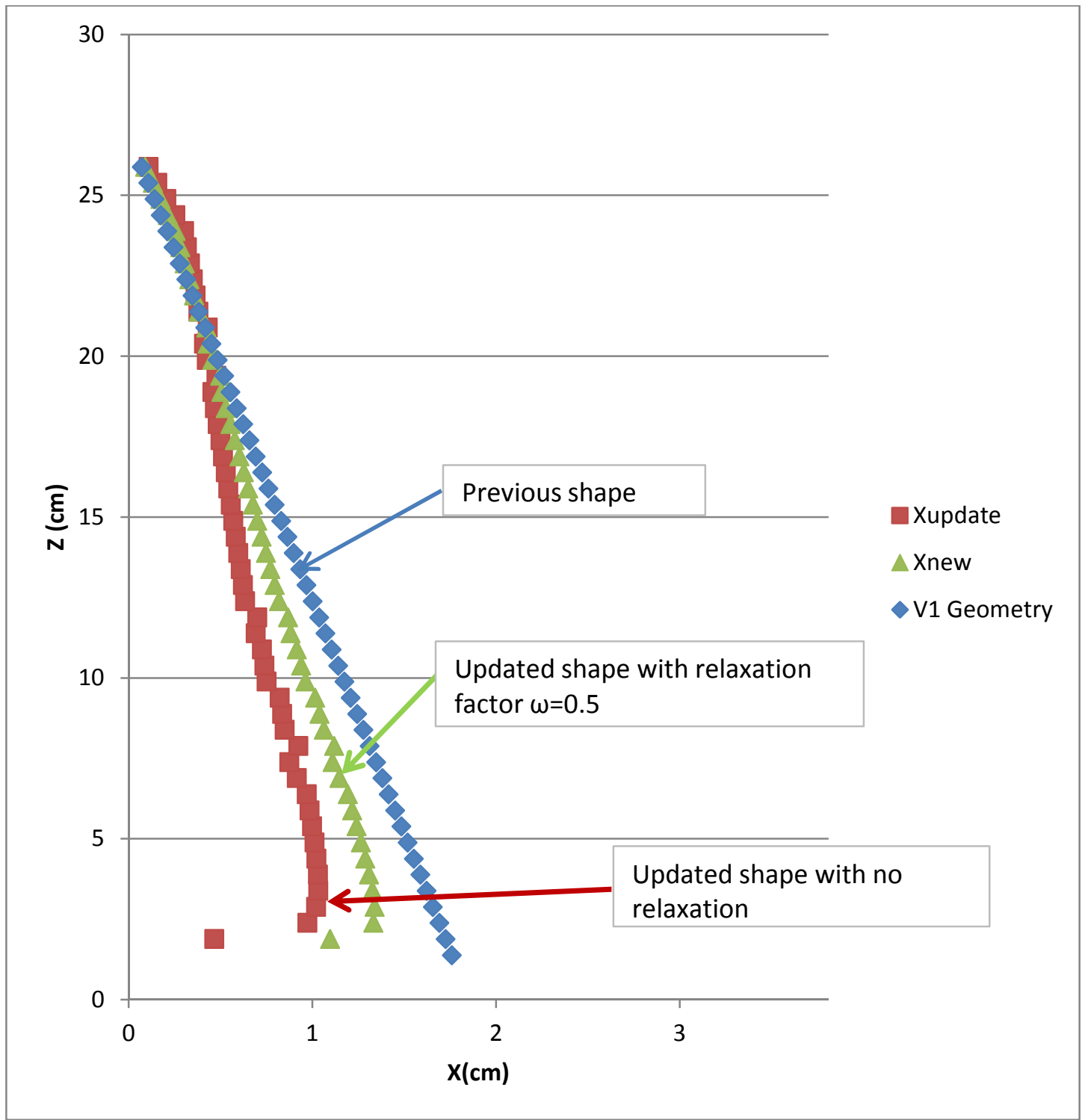

Figure 29. V2 spire geometry. Based on experimental testing of V1 geometry and algorithm output.

A CAD model of the updated spire was generated. A 1:2 scale drawing is included in Appendix B. A CFD simulation was run using Fluent. 


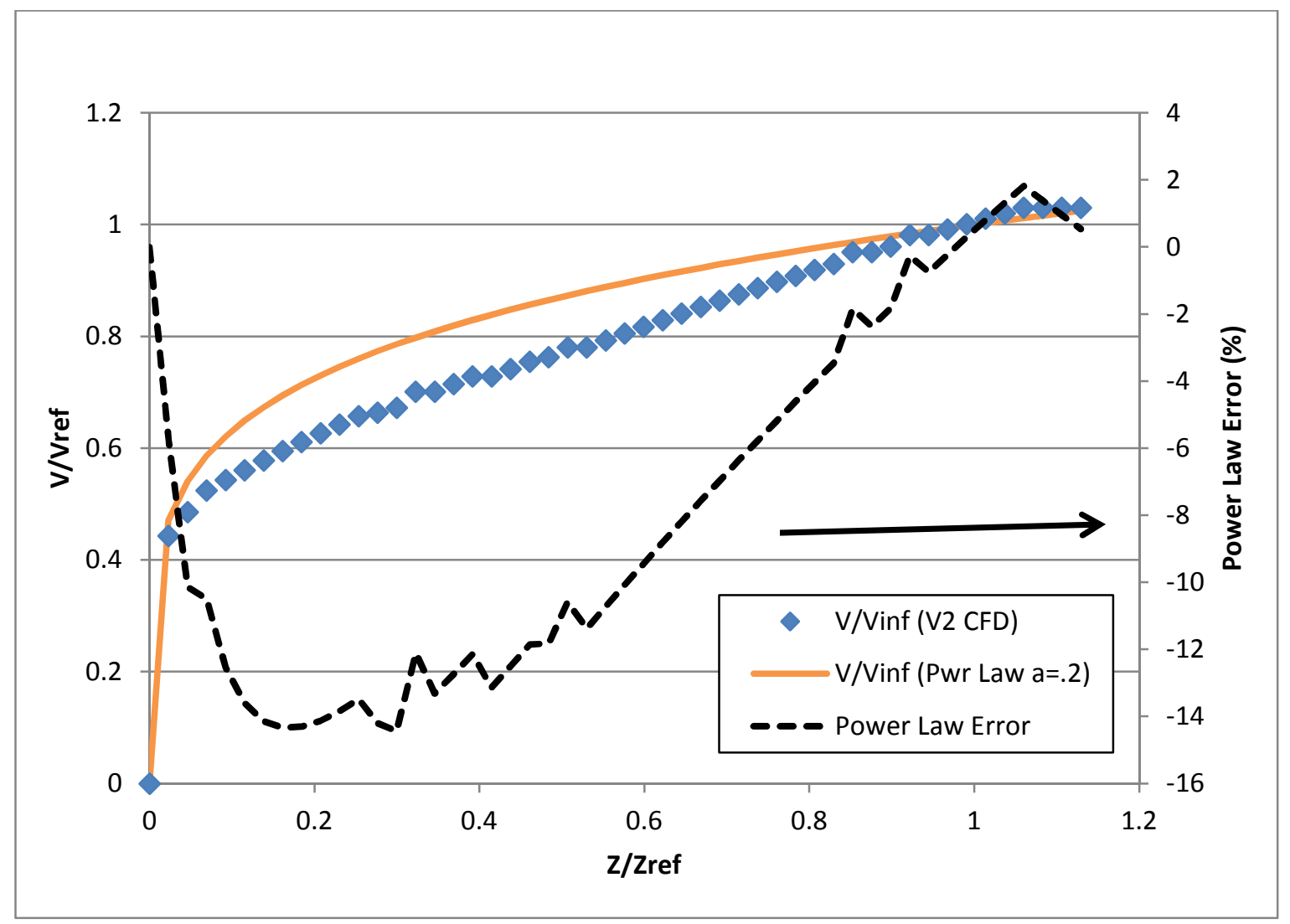

Figure 30 . V2 geometry CFD results. Maximum power law error reduced by $12 \%$ from previous iteration.

It was found that the power law error was reduced to a maximum magnitude of $14.3 \%$, and an average error magnitude of $8.6 \%$. While this trend was in the right direction, the error was too high to consider the velocity profile successfully simulated. The updated transfer function was calculated, and its plot can be seen in Appendix A.

The values of the updated transfer function were slightly lower than the previous ones, which was acceptable. The new transfer function was used to calculate the next geometry iteration. The lowest three points were not included in the shape update. An update relaxation factor $\omega=0.5$ was again used, producing the geometry seen in Figure 31 . 


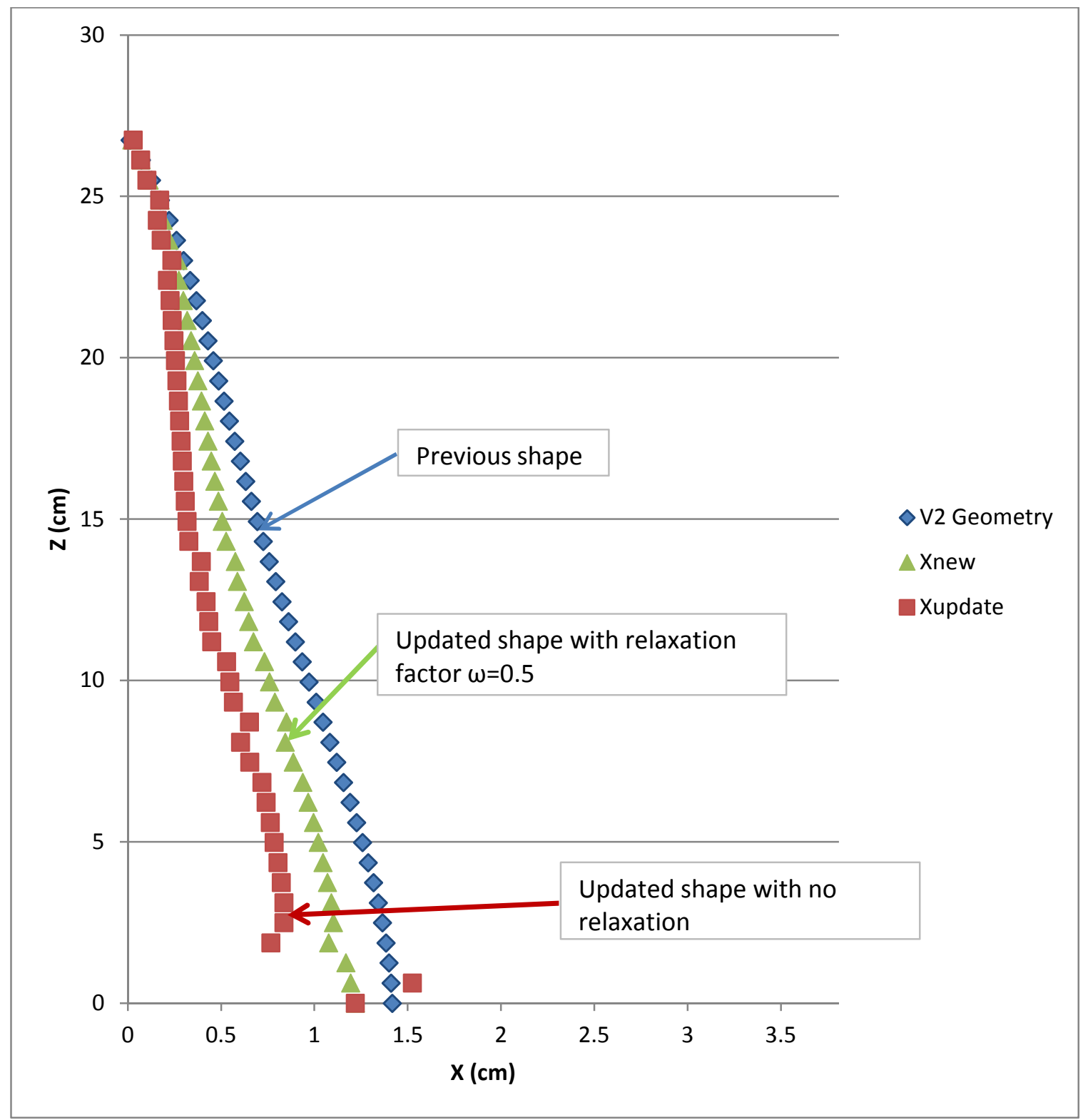

Figure 31. V3 spire geometry. Geometry optimized based on CFD simulation of V2 geometry.

A CAD model was produced, also using a 5th order polynomial to fill in the bottom portion of the shape. A 1:2 scale drawing can be found in Appendix B. The CFD model geometry was updated and re-run. The solver used an iterative method, and to accelerate 
convergence, the solution variable values from the previous analysis were interpolated into the present analysis's initial solution guess.

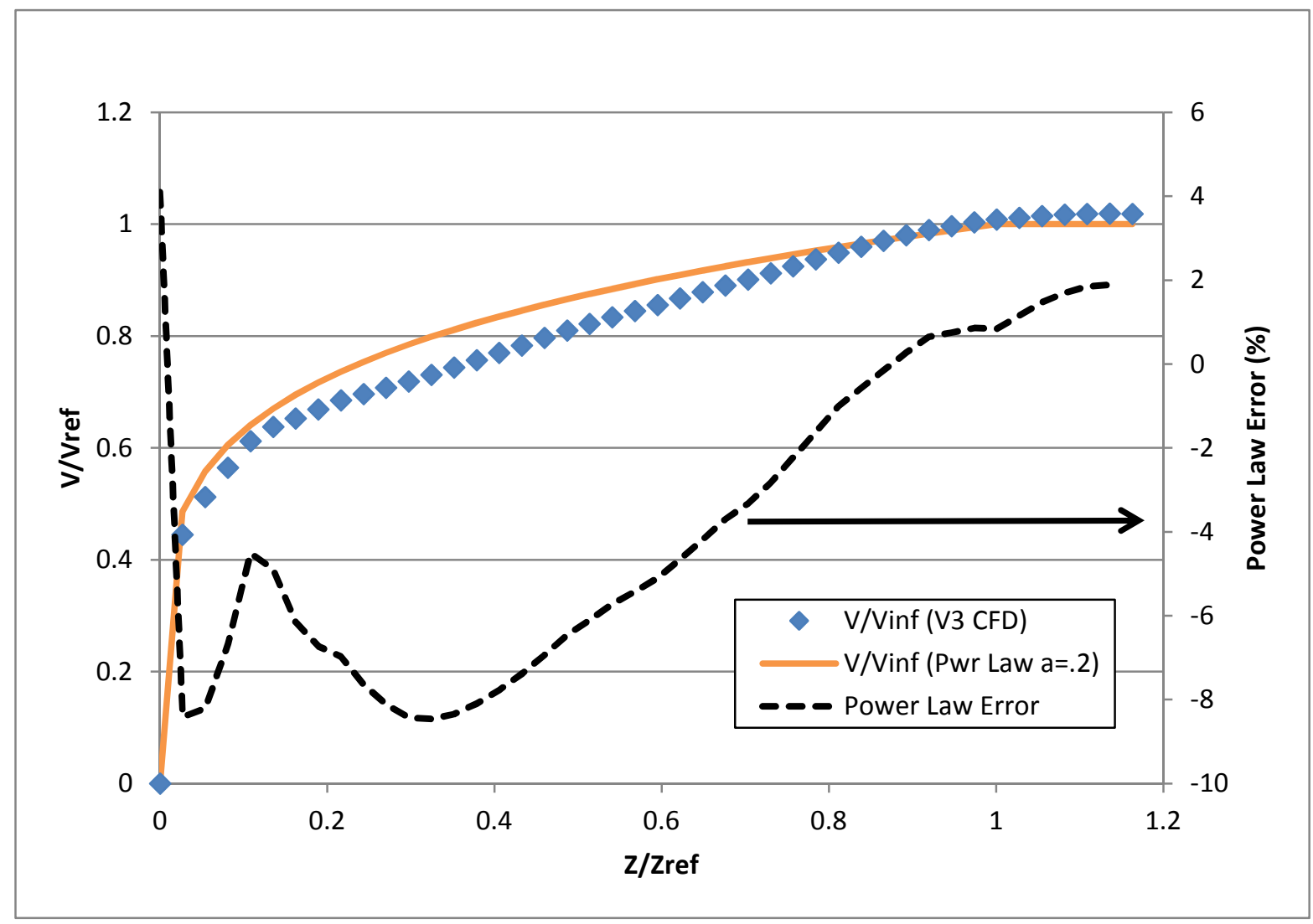

Figure 32. V3 geometry simulation results. Maximum error further reduced $6 \%$ from previous iteration.

The error was further reduced by approximately one half. There then was acceptable agreement with the power law on the extremes of the boundary layer $\left(\frac{Z}{z_{r e f}} \leq 0.1\right.$ and $0.8 \leq \frac{Z}{z_{r e f}}$ ). There was however, a velocity deficit for the majority of the boundary layer, with a maximum error of $8.4 \%$, and an average error magnitude of $4.3 \%$. An additional geometry update cycle was performed. 


\section{Spire Design Four}

An updated transfer function $\Phi(z)$ was computed. A plot can be seen in Appendix

A. Updated shape functions were computed and plotted in Figure 33.

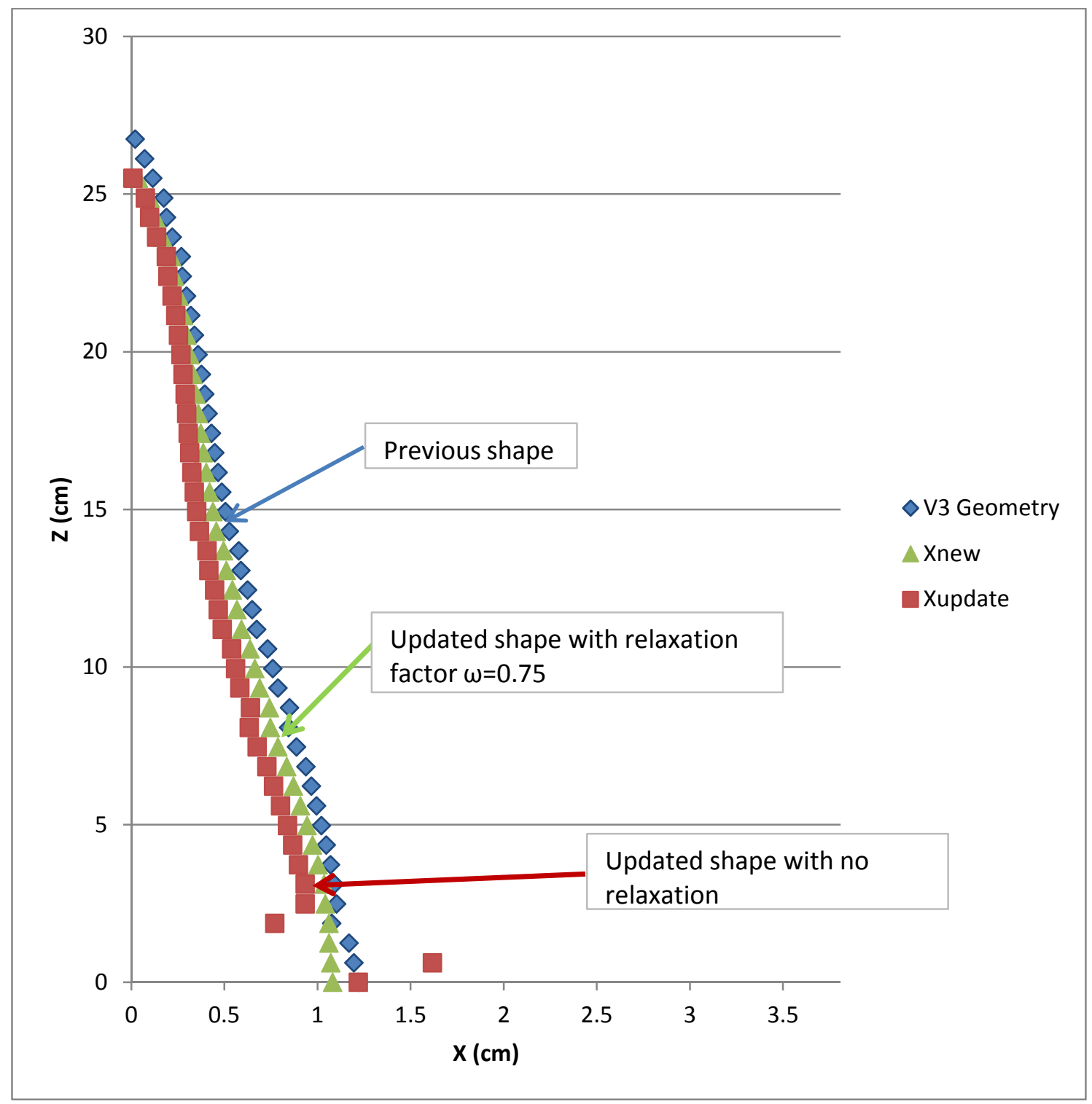

Figure 33. V4 spire geometry. A conservative shape update relaxation factor was chosen.

Because the velocity profile produced by the previous spire iteration had minimal error, a conservative shape update factor $\omega$ of 0.75 was chosen. This yielded a profile 
closer to the previous shape than the output of the update function $\Psi_{\text {update }}(z)$. A cad model was produced, and is seen in Figure 34 with a couple of minor design updates.
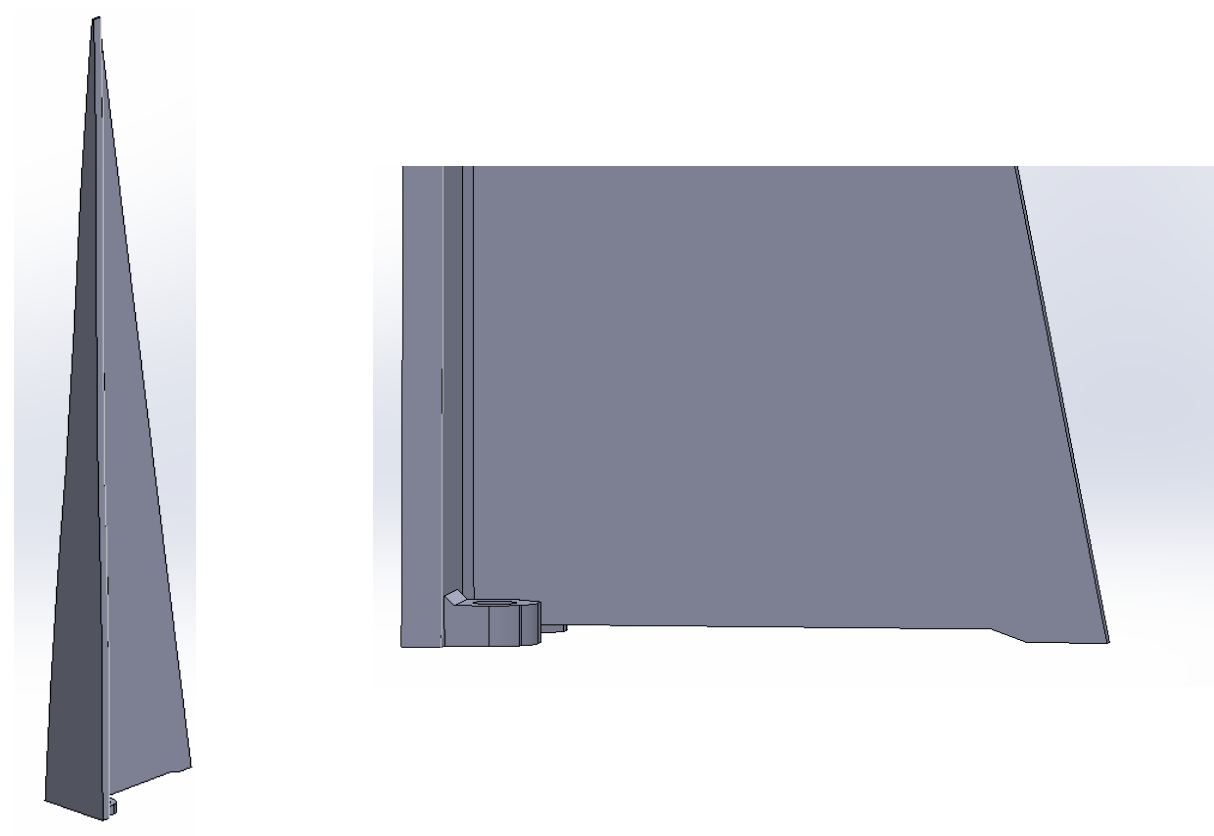

Figure 34. CAD model of V4 geometry. Notch introduced into tail to increase dynamic structural response to flow.

It was known that the turbulence intensity profile of the wind tunnel was to be generated by CFD simulation. Any dynamic structural modes excited by flow would undoubtedly contribute to turbulence in the test section downstream. Obtaining accurate and reasonable results from a static model was difficult enough; an advanced fluidstructure interaction simulation would have taken an unreasonable amount of time. It was thought to minimize the fluid-structure interaction through design.

An obvious deformation mode was the bending of the front triangle of the spire backwards, towards the downstream test section. This mode would be excited by the change in momentum of the upstream flow being diverted by the spire. However, the 
triangular spire "tail", though thin, adds significant bending stiffness. Under reasonable loads, the spire is quite stiff in this regard, up until the tail starts to buckle.

The next obvious deformation mode would be transverse bending or "wagging" of the tail, excited by vortices generated by the front profile. The spires are all $3 \mathrm{~d}$ printed, resulting in loose tolerances on the bottom surface which rest on the mounting surface. The bottom surface of the tail was in contact with the mounting plate non-uniformly across the surface, but on an asperity, close to the mounting feet. Any friction generated by this contact would inadequately resist this deformation mode. Tail motion was observed on one of spires of the first geometry iteration.

To mitigate this, a pocket was designed into the bottom of the tail, resulting in surface contact at the tail extreme, increasing the effectiveness of the contact friction to resist eddy-induced dynamic bending. Additionally the mounting feet were designed thin, to maximize the contribution of the rear contact surface to reacting the aerodynamic load and moment. Ribs were considered to increase the tail bending stiffness, but the front spire face had become quite slight in width by this iteration, and even small ribs were thought to probably change airflow around the spire.

The spires were made using a $3 \mathrm{~d}$ printer, with each split in half to fit into the build envelope of the machine. The two halves were joined with acetone with plastic in solution. The end result can be seen in Figure 35. 

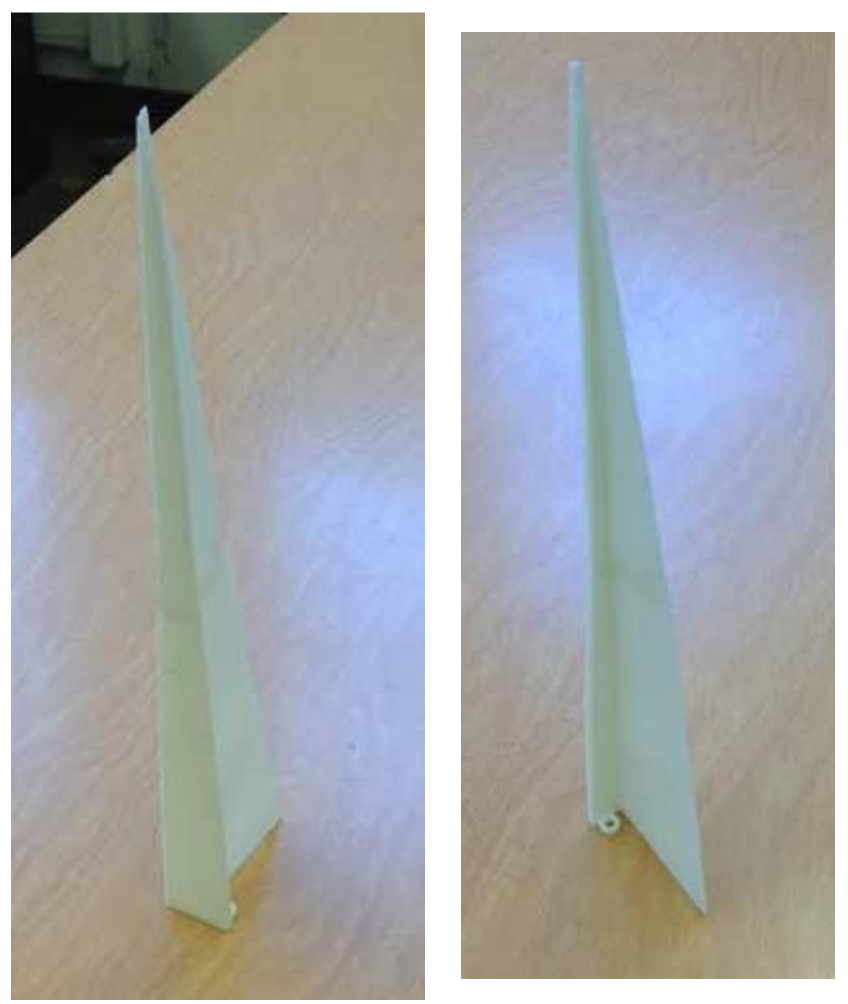

Figure 35. Final iteration of spire geometry. Spires were $3 \mathrm{~d}$ printed in two halves and joined together with acetone.

The spires were assembled into an array with $7.62 \mathrm{~cm}$ spacing between centerlines.

The array was installed into the wind tunnel. The velocity profile seen in Figure 36 was measured. 


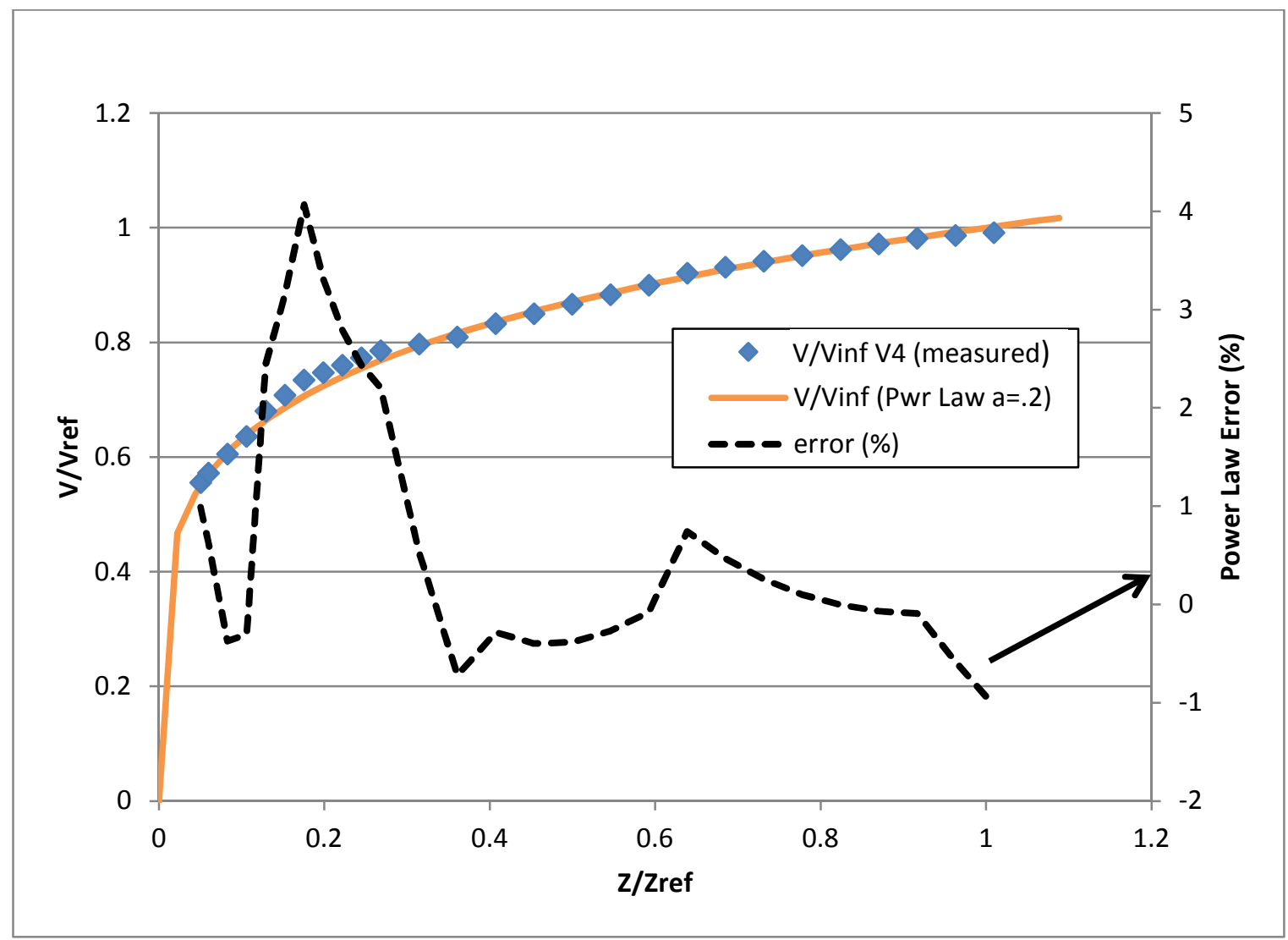

Figure 36. Experimentally measured velocity profile for final geometry iteration. Shape produced by update algorithm yielded excellent agreement with power law.

It was found that this iteration had excellent agreement with the desired power law.

A maximum error of $4.1 \%$ was achieved, with an average error of much less than that. The region with the most error was found to between $Z / Z_{\text {ref }}$ values of $0.1-0.3$. This was part of the boundary layer region where the CFD model tended to underpredict velocity.

Perhaps this effect was captured by the transfer function, and the shape updates overcompensated for during the second and third geometry iterations. Even still, the error was so small that the boundary layer velocity profile initially targeted can be considered successfully simulated using a small-size wind tunnel. 


\section{Characteristics of the Simulated Wind Tunnel}

A plot of velocity measurements is seen in Figure 37. The data indicates a boundary layer height of $22.1 \mathrm{~cm}$. ABLs vary in height, but assuming a boundary layer height of $700 \mathrm{~m}$, typical for a rural environment applicable to a power law exponent of 0.2 , an approximate scale of 1:3000 was achieved.

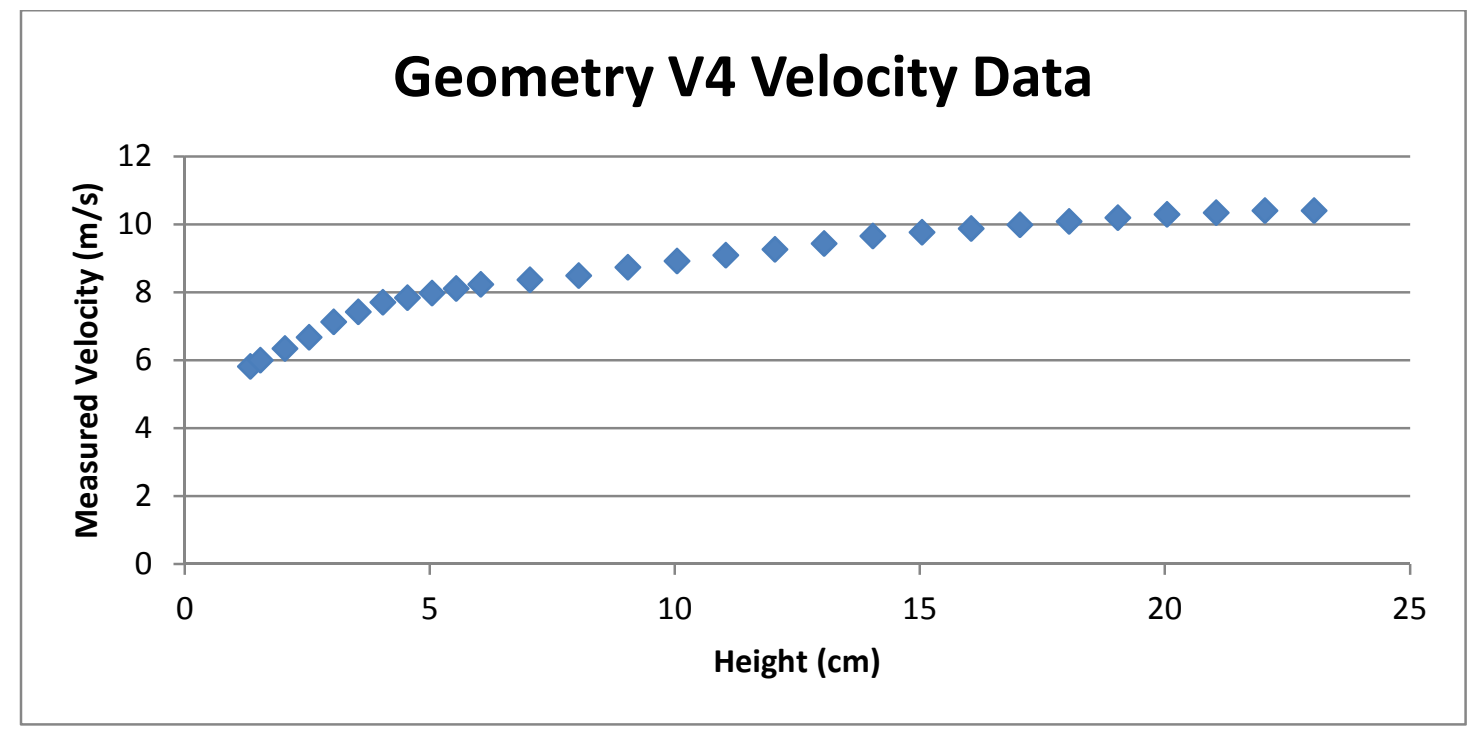

Figure 37. Velocity Plot for Final Geometry Iteration.

An important characteristic of the Atmospheric Boundary Layer is the amount of turbulence of the flow. A turbulence power spectrum fully describes the turbulence characteristics, including information on both the quantity and frequency of the turbulence. To characterize the turbulence spectrum of a flow, velocity data is transformed to the frequency domain. It must be measured with a high sample rate. The most common method is to use a hotwire anemometer, which has a frequency response up to hundreds of kilohertz. 
The frequency spectrum of the small scale ABL wind tunnel was attempted to be characterized using a TSI IFA300 Constant Temperature hotwire anemometer, with a 1210-T1.5 single direction probe. The system was calibrated using the same calibrator as the pitot-tube. The system was plagued with high frequency noise, rendering its data output unusable. Much time was spent trying to troubleshoot the system, but the hot wire sensors failed before the root cause was found.

The final geometry iteration was simulated with CFD. Because the analysis was for a steady state case with a Reynolds-averaging turbulence model, a frequency spectrum was not able to be resolved. Instead, turbulence intensity was computed from turbulence kinetic energy, and plotted in Figure 38.

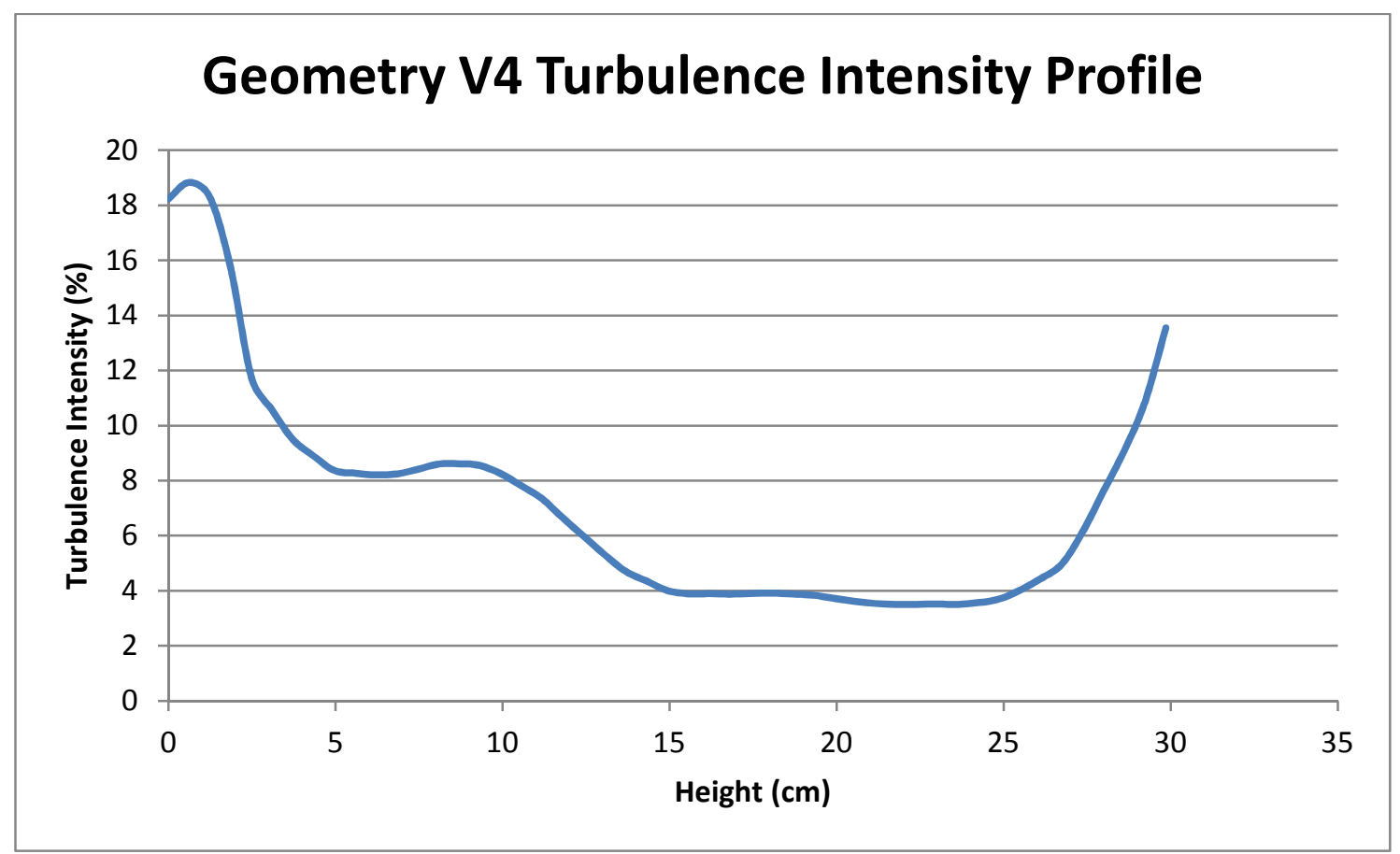

Figure 38. CFD computed turbulence intensity profile. Results are from the test section mid-plane. 
It was found that the turbulence intensity peaks near the floor of the wind tunnel, in the region of the roughness cubes. It dissipated with height, until the ceiling was approached, where turbulence was generated from its boundary layer. Although the behavior captured by the CFD simulation makes physical sense, further testing is required to validate the results. 


\section{CONCLUSIONS}

A small size wind tunnel having test section dimensions of $30.5 \times 30.5 \times 152.4 \mathrm{~cm}$ was shown to be able to simulate the ABL. A CFD analysis showed that at a freestream velocity of $10 \mathrm{~m} / \mathrm{s}$ the natural wall boundary layer development truncated the available test area by $35 \%$. This analysis was partially validated by experimental testing.

It was shown that the classical relations for generating spire geometry could not be extended to a wind tunnel of this size, with the maximum power law error found to be over $25 \%$. An alternative algorithm was proposed that produced nonlinear spire profiles. The algorithm was used in conjunction with CFD simulation and experimental testing. Over the course of four iterations (the first being the geometry produced by the classic empirical relations), a spire shape was produced that simulated an atmospheric boundary layer having an $\alpha=2.0$ power law velocity profile with a maximum error of $4.0 \%$ and an average error of much less than that.

Despite the success in simulating the ABL in a small scale wind tunnel, there is still work that remains to be done. The turbulence in the wind tunnel should be properly measured and a turbulence spectrum generated. A low cost instrument that measures turbulence using microphones could be investigated. The geometry generation algorithm should be optimized and shown to work with different velocity profiles. Additionally, a stand-alone computer program could be created to automate the geometry generation process and obviate the need for cumbersome spreadsheets. 


\section{References}

1) Arya, S. P. (1988). Introduction to Micrometeorology. San Diego, CA: Academic Press.

2) Benson, J. (2005). Boundary layer response to a change in surface roughness (Masters dissertation, University of Reading). Retrieved from http://www.met.rdg.ac.uk/mscdissertations/Boundary\%20layer\%20response $\% 20$ to $\% 20 \mathrm{a} \% 20$ change $\% 20 \mathrm{in} \% 20$ surface $\% 20$ roughness.pdf

3) Burton, T., Jenkins, N., Sharpe, D., \& Bossanyi, E. (2011). Wind Energy Handbook. Chichester, United Kingdom: John Wiley \& Sons, Ltd.

4) Cheng, H., Castro, I. (2002). Near wall flow over urban-like roughness. Boundary Layer Meteorology, 104, 229-259.

5) Counihan, J. (1969). An improved method of simulating an atmospheric boundary layer in a wind tunnel. Atmospheric Environment, 3, 197-214.

6) De Bortoli, M., Natalini, B., Paluch, M., \& Natalini, M. (2002) Part depth wind tunnel simulations of the atmospheric boundary layer. Journal of Wind Engineering and Industrial Aerodynamics, 90, 281-291.

7) Eckert, M. (2006). The Dawn of Fluid Dynamics: A Discipline Between Science and Technology. Weinheim, Germany: Wiley-VCH Verlag GmbH and Co.

8) Garshore, I. S. (1973). A relationship between roughness geometry and velocity profile shape for turbulent boundary layers (Report no. LTR-LA-140). National Research Council of Canada.

9) Hellman, G. (1917). On the Motion of Air in the Lowest Layers in the Atmosphere. Meteorologische Zeitschrift, 34, 273.

10) International Electrotechnical Commission. (1999) Wind turbine generator systems Part 1, International Standard 61400-1.

11) Irwin, H. P. A. H. (1981). The design of spires for wind simulation. Journal of Wind Engineering and Industrial Aerodynamics, 7, 361-366.

12) Isumi, Y. \& Caughey, S.J. (1976) Minnesota 1973 atmospheric boundary layer experiment data report. Eviron. Res. Pap., No. 547, Air Force Cambridge Research Laboratories, Bedford, Ma.

13) Kaltschmitt, M., Streicher, W., Wiese, A. (2007). Renewable Energy: Technology, Economics, and Environment. Berlin, Germany: Springer. 
14) Lopes, M. F. P., Gomes, M. G., \& Ferreira, J. G. (2008). Simulation of the atmospheric boundary layer for model testing in a short wind tunnel. Experimental Techniques, 32, 4, 36-43.

15) Peterson, E. W., Busch, N. E., Jensen, N. O., Hcjstrup, J., Kristensen, L. \& Petersen, E. L.: 1978, The Effect of Local Terrain Irregularities on the Mean Wind and Turbulence Characteristics Near the Ground, WMO-No. 510. (Symp. on BL Physics applied to Air Pollution, Norrkoping) pp. 45-50.

16) Peterson, E.L., Mortensen, N., Landberg, L., Højstru, J., \& Frank, H.P. (1998). Wind power meteorology. Part I: Climate and turbulence. Wind Energy, 1, 1, 2-22.

17) Stull, R. B. (1988). An Introduction to Boundary Layer Meteorology. Boston, MA: Kluwer Academic Publishers.

18) Teunissen, H. W. (1975). Simulation of the planetary boundary layer in a multiplejet wind tunnel. Atmospheric Environment, 9, 145-174.

19) U.S. Energy Information Association. (2013). International Energy Outlook 2013 (Report no. DOE/EIA-0484(2013). Retrieved from U.S. Energy Information Association website: http://www.eia.gov/forecasts/ieo/pdf/0484(2013).pdf

20) Wieringa, J. (1993). Representative roughness parameters for homogeneous terrain. Boundary Layer Meteorology, 63, 323-363.

21) Wooding, R. A., Bradley, E. F., Marshall, J. K. (1973). Drag due to regular arrays of roughness elements of varying geometry. Boundary Layer Meteorology, 5, 285.

22) Zhi-qing, W. (1982). Study on correction coefficients of laminar and turbulent entrance region effect in round pipe. Applied Mathematics and Mechanics, $3,433-446$. 
Appendix A

Transfer Function $\boldsymbol{\Phi ( z )}$ Plots
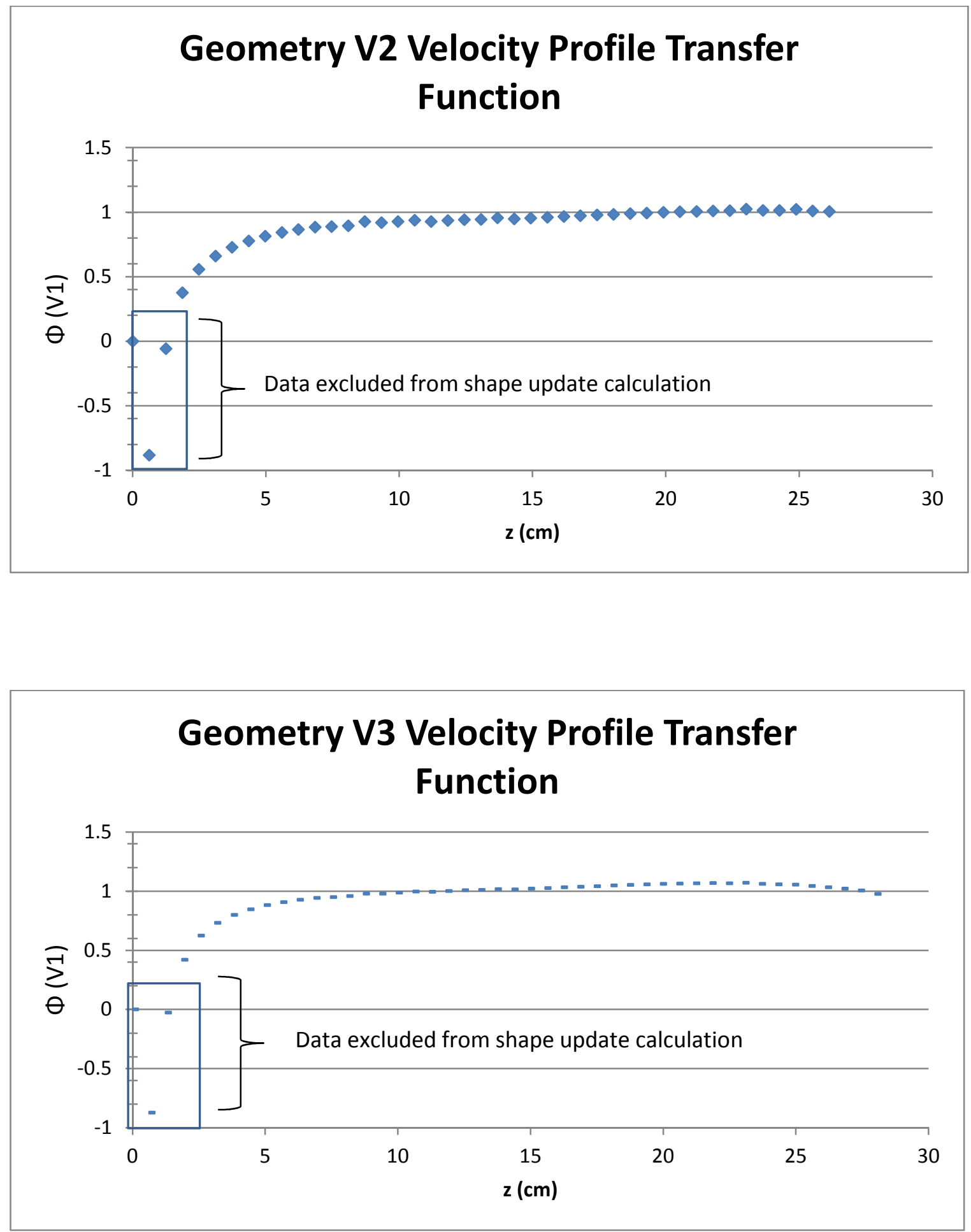
Appendix B

1:2 Scale Drawings of Spire Profiles
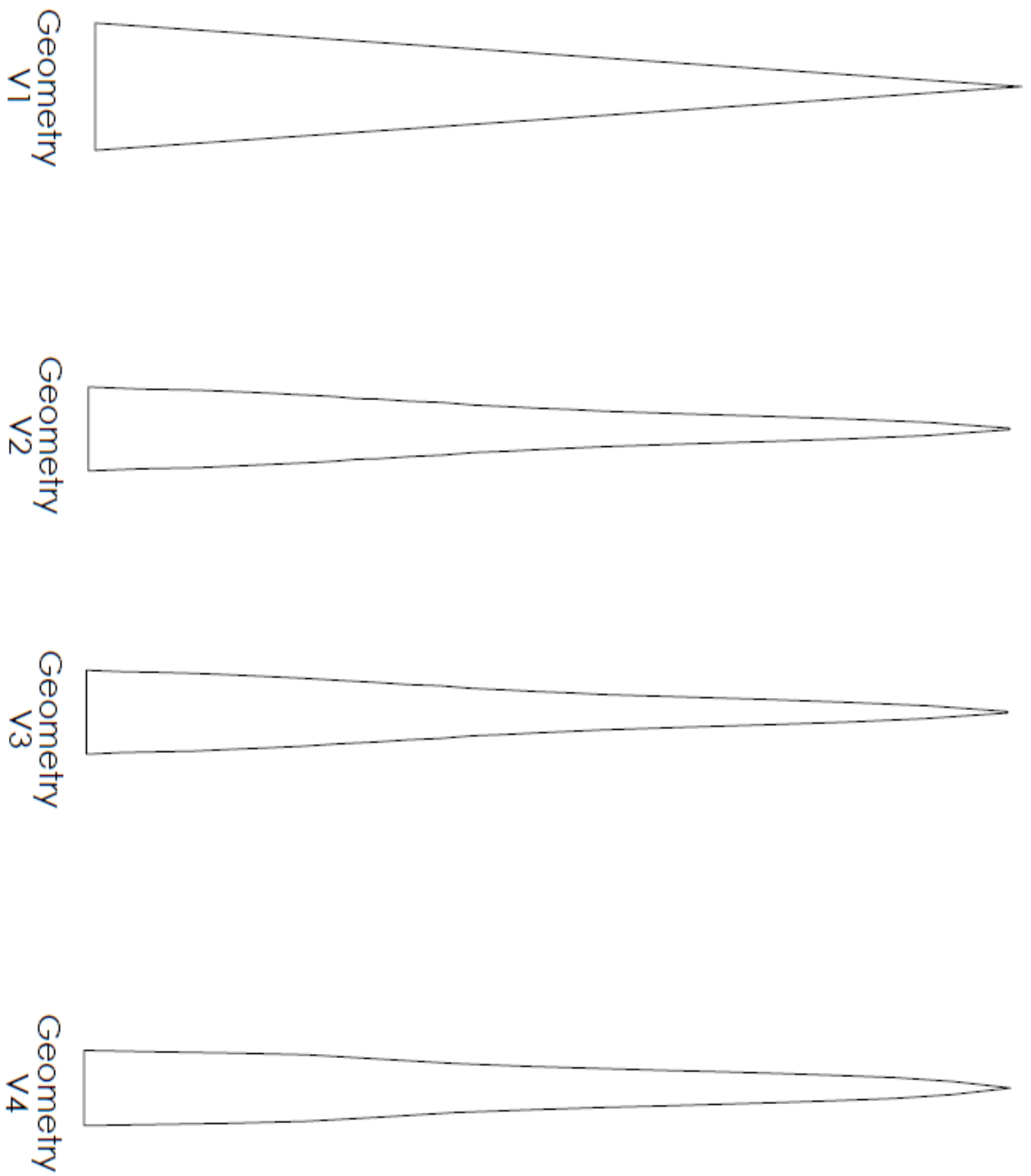